\title{
A Review of Microwave Thermography Nondestructive Testing and Evaluation
}

\author{
Hong Zhang ${ }^{1, *}$, Ruizhen Yang ${ }^{2}$, Yunze $\mathrm{He}^{3, *}$, Ali Foudazi ${ }^{4}$, Liang Cheng ${ }^{5}$ and Guiyun Tian ${ }^{5}$ \\ 1 School of Electronic and Information Engineering, Fuqing Branch of Fujian Normal University, \\ Fuzhou 350300, China \\ 2 Department of Civil and Architecture Engineering, Changsha University, Changsha 410022, China; \\ xbaiyang@163.com \\ 3 College of Electrical and Information Engineering, Hunan University, Changsha 410082, China \\ 4 Electrical and Computer Engineering Department, Missouri University of Science and Technology, Rolla, \\ MO 65409, USA; ali.foudazi@mst.edu \\ 5 School of Electrical and Electronic Engineering, Newcastle University, Newcastle upon Tyne NE1 7RU, UK; \\ liangcheng85@gmail.com (L.C.); g.y.tian@newcastle.ac.uk (G.T.) \\ * Correspondence: zhhgw@hotmail.com (H.Z.); yhe@vip.163.com (Y.H.); \\ Tel.: +86-157-1591-8377 (H.Z.); +86-134-6769-8133 (Y.H.)
}

Received: 21 March 2017; Accepted: 10 May 2017; Published: 15 May 2017

\begin{abstract}
Microwave thermography (MWT) has many advantages including strong penetrability, selective heating, volumetric heating, significant energy savings, uniform heating, and good thermal efficiency. MWT has received growing interest due to its potential to overcome some of the limitations of microwave nondestructive testing (NDT) and thermal NDT. Moreover, during the last few decades MWT has attracted growing interest in materials assessment. In this paper, a comprehensive review of MWT techniques for materials evaluation is conducted based on a detailed literature survey. First, the basic principles of MWT are described. Different types of MWT, including microwave pulsed thermography, microwave step thermography, microwave pulsed phase thermography, and microwave lock-in thermography are defined and introduced. Then, MWT case studies are discussed. Next, comparisons with other thermography and NDT methods are conducted. Finally, the trends in MWT research are outlined, including new theoretical studies, simulations and modelling, signal processing algorithms, internal properties characterization, automatic separation and inspection systems. This work provides a summary of MWT, which can be utilized for material failures prevention and quality control.
\end{abstract}

Keywords: infrared thermography; NDT; microwave thermography; volumetric heating; material

\section{Introduction}

Infrared (IR) thermography plays an important role in structural health monitoring (SHM) [1] and non-destructive testing (NDT) [2]. IR thermography has great potential and advantages, including fast inspection time, high sensitivity and spatial resolution owing to commercial IR cameras' ability to detect inner defects as a result of heat conduction. It can be split into two categories: passive and active. For the passive approach, the IR camera is used to measure the temperature of materials under test without any external excitation source. The passive thermography configuration is illustrated in Figure 1a. In many industrial processes, passive thermography has been used in production and predictive maintenance [3]. While passive thermography allows qualitative analyses to be performed, active thermography is both qualitative and quantitative [4].

Contrary to the passive approach, an external thermal excitation is required for active thermography. The known characteristics of this external excitation enable depth quantification 
in composites' debonding detection [5]. As shown in Figure 1b, the configuration of the active infrared approach is similar to that of the passive approach, except for the utilization of an excitation source to generate a distinctive thermal contrast. As illustrated in Figure 1b, the IR camera is situated on the same side of the excitation source in reflection configuration. For transmission configuration, the IR camera is situated on the opposite side of the excitation source. The IR camera is synchronized with the excitation source by a control unit. A computer is required to process and display the obtained thermal images. To improve contrast and quantify defects, active thermography is often performed with advanced signal processing methods. Normally, the reflection mode is suitable for detecting defects situated near the surface, while deeper defects can be detected in the transmission mode. However, the transmission approach cannot be used in some cases where the target is inaccessible [6-8].

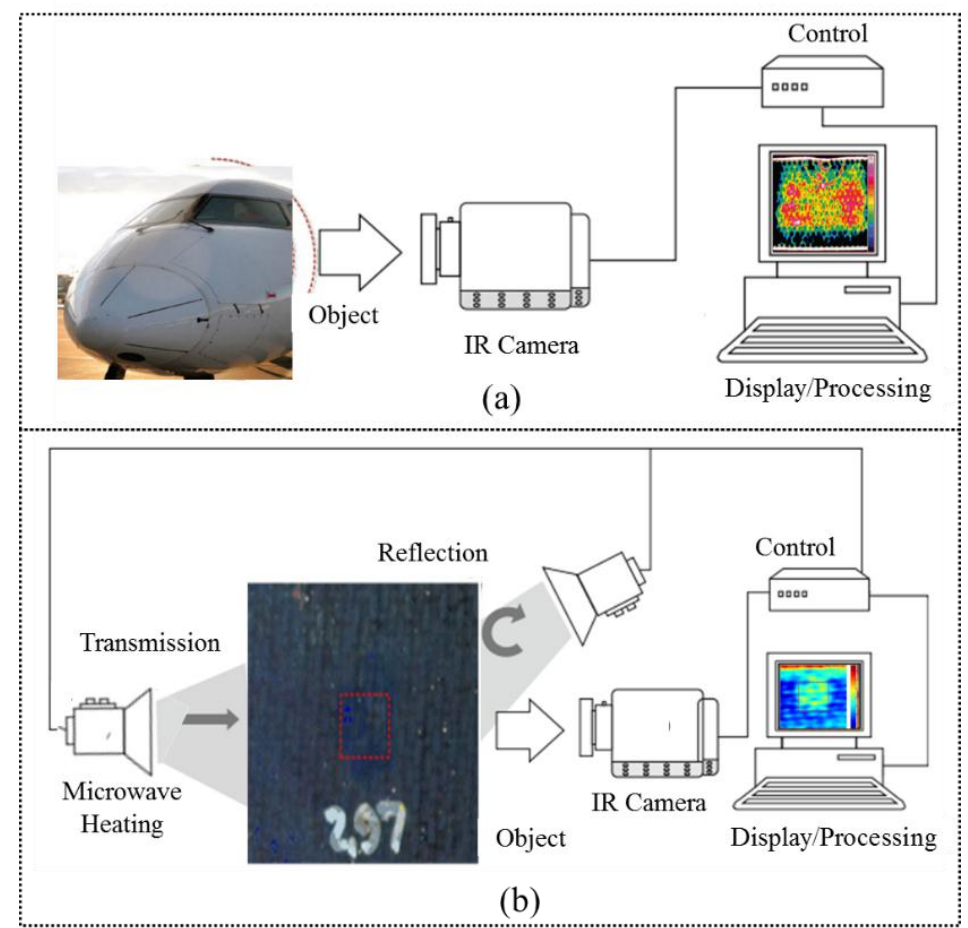

Figure 1. MWT setup for (a) the passive approach and (b) the active approach.

Depending on the external thermal excitation, different active thermography methods have been developed, such as pulsed thermography (PT) [9], step thermography (ST) [10] and modulated thermography (MT) or so-called lock-in thermography (LT) [11]. Finally, there is pulsed phase thermography (PPT) [12], developed by Maldague and Marinetti in 1996, which combines the advantages of PT and MT [13,14].

Various physical heating sources have been adopted as thermal stimulation sources, such as thermal lamps, lasers, ultrasound devices, and electromagnetic waves. Accordingly, laser thermography [15], ultrasonic thermography and eddy current thermography [16,17] were developed. Taking eddy current thermography as an example, it combines the advantages of IR thermography and eddy current testing, such as being fast and non-contact [18-21]. Eddy current thermography can heat many materials such as metals and carbon fiber reinforced polymer (CFRP) with eddy current heating. However, it only works for conductive materials [22-24], therefore, the excitation source needs to be chosen according to the specific problem. In the last decade, researchers have shown an increased interest in microwave heating techniques. Microwave heating has been exhibited advantages of rapid heat transfer (due to volumetric heating), efficiency, heating uniformity, compact equipment, and being easy to control, etc. Meanwhile, microwave heating has emerged as a powerful platform due to dielectric loss and eddy current heating with different materials under test. So far, built microwave 
thermography devices have shown some unique advantages such as: (1) microwaves will produce reflection, scattering, transmission at a discontinuous interface. With microwave signal reflection and scattering in the defect area, less microwave energy can be used for heating, and the temperature raise in a defect area is slower than in a non-defect area during microwave heating. IR cameras will capture this abnormal thermal image which will strengthen the effectiveness of defect detection; (2) the heating pattern of microwave heating is relatively uniform, volumetric and selective, and can be achieved in a short time; (3) microwave heating is easy to control, and it is easy to implement different heating function modulations. However, it is necessary to restrict microwave leakage as they are dangerous to human health, therefore, the leakage of the microwaves needs to be kept below a certain recommended level. Generally, in industry microwave heating is operated from $890 \mathrm{MHz}$ to $2.45 \mathrm{GHz}$ to minimize any possible interference with communication services [25].

Thermography has been associated with microwaves in numerous applications. MWT has been employed by some scientists to detect wet rotten wood [26], mines and surrogate signatures $[27,28]$. MWT has also been used to inspect and characterize various kinds of materials and phenomena, such as debonding and delamination in composite materials [29]. So far, although there are several review works [30-44], they have been limited to a specific field such as composite or renewable energy, so a review of MWT in the material detection field which includes the principles, advantages and disadvantages, developments and research trends is still needed. In this paper, a comprehensive review of MWT techniques for material evaluation has been provided, based on a detailed literature survey.

The overall structure of this paper includes the following: the principle of MWT is presented in Section 2. Then, typical types of MWT applications are summarized in Section 3. Section 4 reviews the development of MWT with case studies. Then, a comparison and discussion are provided in Section 5. Trends are shown in Section 6. Finally, the conclusions are outlined in Section 7.

\section{Principle of Microwave Thermography}

The principles of MWT mainly include microwave heating and 3D heat conduction. These are analyzed theoretically in the following subsections.

\subsection{Microwave Based Heating}

The heating style of microwave thermography can be divided into volume heating and surface heating [45], therefore the heating process can be divided into volumetric heating (i.e., dielectric loss heating) and surface heating (i.e., eddy current heating).

\subsubsection{Dielectric Loss Heating}

For dielectric materials, such as glass fiber composite materials, microwave heating is volumetric heating (i.e., dielectric loss heating). Considering glass fiber composites for instance, material dielectric loss in the microwave radiation field will generate heat. The dissipated power $P$ per unit volume can be expressed as follows [46]:

$$
P=2 \pi f \varepsilon_{0} \varepsilon^{\prime \prime} E^{2}
$$

where $f$ is the frequency of an electric field, $E$ is the RMS value of the electric field, $\varepsilon_{0}$ is the permittivity of air, and $\varepsilon^{\prime \prime}$ is the relative loss factor. Without considering the heat diffusion, the temperature change per unit at heating time $t$ with a continuous microwave source is [46]:

$$
T(t)=\frac{P t}{\rho C p}=\frac{\omega \varepsilon_{0} \varepsilon^{\prime \prime} E^{2}}{\rho C p} t
$$

where $\rho$ is the density of the material and $C p$ is heat capacity. Obviously, with constant microwave parameters and constant properties of the material under test, the temperature increases linearly with time (during a short period of time). 
The basic principles of MWT volumetric heating are shown in Figure 2a: firstly, a microwave excitation module is used to generate a microwave radiation field; secondly, microwaves penetrate the material under test, and the medium molecules will move at the frequency of the electric field which generates heat and eventually is converted into Joule heat, which then will transfer around the material based on the diffusion equation; finally, an IR camera is utilized to obtain the temperature variation in the material under test. Due to the differences in density and heat capacity between the materials under test and defects, information about surface and internal defects can be obtained. Thus, the processes of MWT for dielectric materials evaluation are based on microwave radiation, dielectric loss to generate Joule heat, heat transfer, and IR radiation.

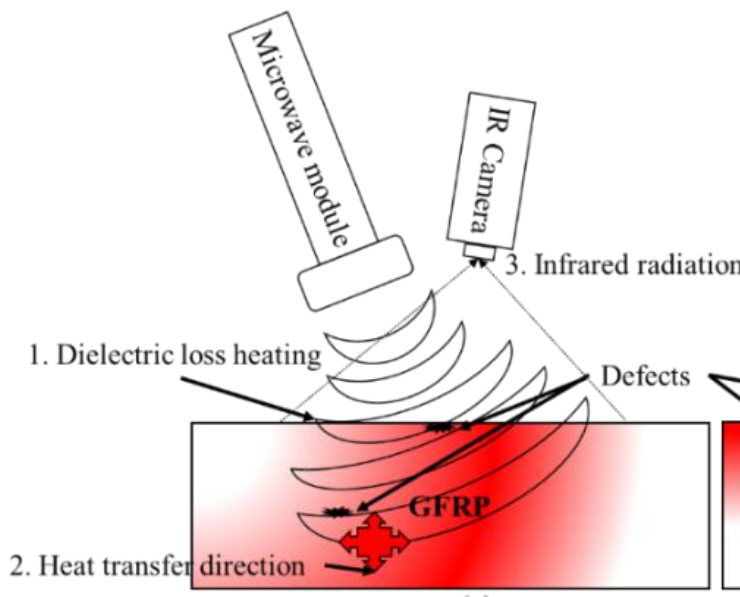

(a)

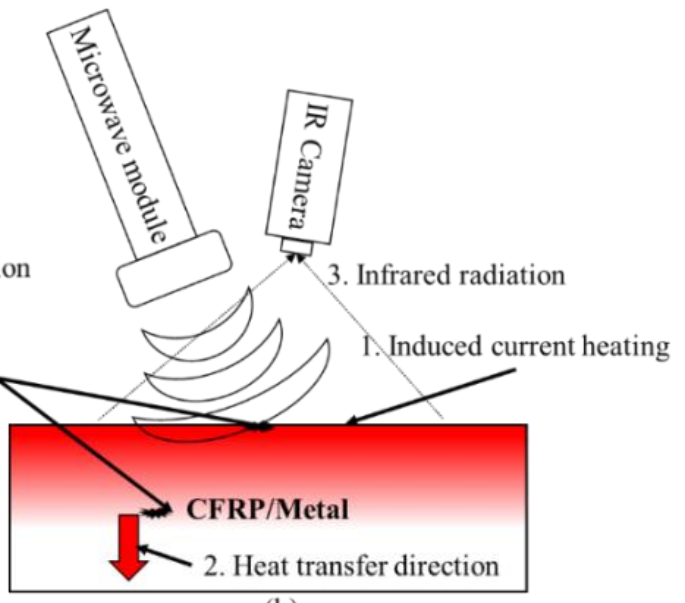

(b)

Figure 2. Basic schematic of MWT: dielectric material (a) and conductive material (b).

\subsubsection{Eddy Current Heating}

For conductive materials, like metals and carbon fiber composites, microwave heating is eddy current heating. Since the material under test is electrically conductive, microwaves cannot penetrate the conductor material. Thus, the principle of microwave heating is that the energy is radiated to the conductive material surface by microwaves, an alternating electric field is generated, then, induced surface currents are excited from the alternating electric field, resulting in an alternating magnetic field. Next, a vortex electric field is generated by this alternating magnetic field, the vortex electric field promotes the movement of electrons which will generate Joule heat. Finally, the conduct material is heated by Joule heat as shown in Figure $2 \mathrm{~b}$. Power $P$ and heat $Q$ generated by eddy current heating can be expressed as [47]:

$$
\begin{gathered}
P \sim I_{\text {inductor }}^{2} \sqrt{\frac{\mu f}{\sigma}} \\
Q=P t \sim I_{\text {inductor }}^{2} \sqrt{\frac{\mu f}{\sigma}} t
\end{gathered}
$$

where, $I_{\text {inductor }}$ is the current flowing through the inductor, $\sigma$ is the conductivity $(\mathrm{S} / \mathrm{m}), \mu$ is the magnetic permeability of the material under test and $f$ is the frequency of the induced current. It is observed that with a stable induced current and induced current frequency, the generated heat is directly proportional to the microwave excitation time and it is inversely proportional to the square root of the conductivity. However, due to the presence of heat transfer and dissipation problems during actual applications, MWT must be corrected in order to minimize the measurement error. 
Due to the skin effect, induced current depth (within the skin depth) in the conductive material is an extremely important factor. The skin depth can be obtained by the following equation [48]:

$$
\delta=\frac{1}{\sqrt{\pi \mu \sigma f}}
$$

where $f$ is the microwave's frequency, $\sigma$ is the conductivity $(\mathrm{S} / \mathrm{m})$, and $\mu$ is the magnetic permeability $(\mathrm{H} / \mathrm{m})$ of the material under test. A typical conductivity of CFRP is probably $1000 \mathrm{~S} / \mathrm{m}$, and the permeability is around 1. With $2.4 \mathrm{GHz}$ microwave excitation, the skin depth is about $0.002 \mathrm{~mm}$. Therefore, MWT belongs to the surface heating category as only the surface of the CFRP is heated.

\subsection{D Heat Transfer and Temperature Field}

Heat $Q$ generated by dielectric loss or the Joule heat will be conducted from inside to the surrounding material. The heat conduction equation is a time-dependent heat diffusion equation [49]:

$$
\frac{\partial T}{\partial t}=\underbrace{\frac{k}{\rho C_{p}}\left(\frac{\partial^{2} T}{\partial x^{2}}+\frac{\partial^{2} T}{\partial y^{2}}+\frac{\partial^{2} T}{\partial z^{2}}\right)}_{\text {Thermal diffusion }}+\underbrace{\frac{1}{\rho C_{p}} Q(x, y, z, t)}_{\text {Microwave heating }}
$$

where, $T=T(x, y, z, t)$ is the temperature distribution of the surface, $k$ is the material thermal conductivity $(\mathrm{W} / \mathrm{m} \times \mathrm{K}), C_{p}$ is specific heat capacity $(\mathrm{J} / \mathrm{kg} \times \mathrm{K}), \rho$ is the density $\left(\mathrm{kg} / \mathrm{m}^{3}\right)$, and $Q(x, y, z, t)$ is the heat generation function with microwave heating (the dielectric loss heating or eddy current heating). A surface temperature distribution will eventually reflect disturbances of the electromagnetic and thermal fields. Therefore, MWT has the potential to characterize and track the property variations of the material, such as magnetic permeability, electrical conductivity, permittivity, thermal conductivity, thermal diffusivity, etc. In addition, the depth of defects can be quantified. The heat generated by Joule heat will propagate a certain distance within the material in the form of heat waves. The penetration depth $\delta_{\text {th }}$ of these heat waves is [50]:

$$
\begin{aligned}
& \delta_{t h} \approx 2 \sqrt{\alpha t} \\
& \alpha=(k / \rho C p)
\end{aligned}
$$

where, $\alpha$ is the thermal diffusivity, and $t$ is the observation time. $\alpha$ can be expressed as a function of the density of the material $\rho$, heat capacity $C p$ and thermal conductivity $k$, as shown in Equation (8). It shows that the penetration depth of heat $\delta_{t h}$ is proportional to the square root of $t$ and $\alpha$ [11]. In the case of a modulated thermal wave, the length of thermal diffusion decides the penetration depth, which can be found from the following equation [11]:

$$
\mu_{t}=\sqrt{\frac{2 k}{\omega \rho C p}}=\sqrt{\frac{\alpha}{\pi f}}
$$

where, $\rho$ is density, $k$ is thermal conductivity, $\alpha$ is thermal diffusivity, $C p$ is heat capacity, and $f$ is the frequency of the thermal wave. The penetration depth is proportional to the reciprocal of the square root of $f$ and $\alpha$. In other words, the detection depth varies according to the modulation frequency. In summary, the detection ability of microwave thermography is closely related to the electrical, dielectric and thermal properties of the material under test. 


\section{Types of Microwave Thermography}

\subsection{Classification of Excitation Configuration}

According to the excitation configurations of microwave heating, MWT can be divided into microwave pulsed thermography (MPT),microwave pulsed phase thermography (MPPT), microwave lock-in thermography (MLT) [51], or microwave step thermography (MST), also known as microwave time-resolved thermography [52]. With MPT, the material under test is heated by a small period of microwave excitation as shown in Figure 3a. The variation of temperature is observed in the heating phase and the cooling phase. For MST, the sample is step heated by a long pulse as shown in Figure $3 b$, and the variation of temperature is observed in the heating phase. As shown in Figure $3 c$, the material under test is heated by a periodic amplitude modulated microwave with MLT and the periodic temperature change is captured. A square pulsed modulated excitation is used to derive phase information from multiple thermal waves with one inspection. The influence of non-uniform heating is been reduced and deeper defects can be displayed with a higher contrast. A pulse excitation signal is used by MPPT. Phase analysis is carried out in the frequency domain [13]. Predictably, microwave frequency modulated thermography will employ a frequency modulated microwave excitation in order to derive phase information. From the above analysis, the conclusion can be reached that: MPT and MST analyze the temperature of thermal imaging in the time domain, which is affected by surface emissivity variations and non-uniform heating; MLT obtains information in the frequency domain such as phase, which can suppress the influence of the surface emissivity variations and non-uniform heating. However, the MLT inspection system requires a long measurement time and it is relatively complex.

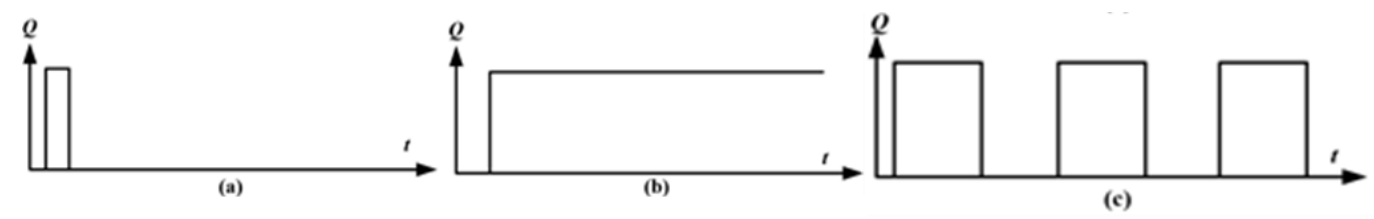

Figure 3. Excitation functions of MWT: (a) MPT; (b) MST; (c) MLT.

Comparisons among MPT, MST, MLT, and MPPT are listed in Table 1. Due to the use of an IR camera, all of them exhibit high sensitivity, high resolution, full-field detection and good visibility. In addition, quantification information can be achieved based on the heat conduction:

1. MPT can be fast and easily deployed. Surface temperature gradients will be introduced not only from defects, but also local variations in surface emissivity and non-uniform heating. A long inspection time is required for a thick material. In addition, the material could be damaged due to the high heating energy.

2. MST is a time-resolved method and it can be used to quantify defect depth. However, the radiation from the heat source in the continuous heating process could deteriorate the temperature measurements. Also, the non-uniform heating and surface emissivity variation have adverse effects on defect evaluation.

3. MLT generally required less excitation energy than MPT. MLT exhibits a higher sensitivity than MPT. The phase data can be extracted which is independent of surface emissivity and heating variations. Tests are repeated with various frequencies and it becomes a time-consuming process to detect defects with various depths. However, MLT offer a compromise with a better depth resolution.

4. MPPT combines the advantages of MPT and MLT. MPPT is less sensitive to non-uniform heating and surface emissivity than MLT as only phase information can be obtained. Moreover, MPPT employed a short excitation pulse which is faster than MLT and wide frequency spectra can be obtained. However, with increasing frequency, the transferred energy is decreased with MPPT. With post processing algorithm, MPPT exhibits better detect ability and resolution than MPT for deeper defects. 
Table 1. Comparisons among MPT, MST, MLT and MPPT.

\begin{tabular}{|c|c|c|}
\hline Techniques & Strength & Limitation \\
\hline Microwave pulsed thermography [13] & $\begin{array}{l}\text { Full-field, high resolution, high sensitivity, good visibility, } \\
\text { quantification, fast, easy deployment }\end{array}$ & $\begin{array}{l}\text { Small depth, long time for thick material, emissivity } \\
\text { and non-uniform heating dependence, high power }\end{array}$ \\
\hline Microwave step thermography [52] & $\begin{array}{l}\text { Full-field, high resolution, high sensitivity, good visibility, } \\
\text { quantification, fast, easy deployment, time-resolved }\end{array}$ & $\begin{array}{l}\text { The radiation from heat source in the continuous } \\
\text { heating process could have a negative influence on } \\
\text { temperature measurements of MUT, emissivity, } \\
\text { and non-uniform heating dependence }\end{array}$ \\
\hline Microwave lock-in thermography [51] & $\begin{array}{c}\text { Full-field, high resolution, higher sensitivity, good visibility, } \\
\text { quantification, low power, emissivity independence, } \\
\text { elimination of non-uniform heating }\end{array}$ & $\begin{array}{l}\text { Compromise between depth and depth } \\
\text { resolution, time-consuming, }\end{array}$ \\
\hline Microwave pulsed phase thermography & $\begin{array}{l}\text { Full-field, high resolution, high sensitivity, good visibility, } \\
\text { quantification, fast, emissivity independence, elimination of } \\
\text { non-uniform heating, greater depth and resolution, better detectability }\end{array}$ & $\begin{array}{l}\text { Post signal processing, } \\
\text { energy attenuation with frequency }\end{array}$ \\
\hline
\end{tabular}




\subsection{Classification by Heating Style}

MWT can be classified into surface heating thermography, volume heating thermography, and abnormal heating thermography [14,45]. In Figure 4a, for eddy current heating, MWT can be also called surface heating thermography (SHT). Due to the great permeability, the skin depth is very small [53-55]. Thus, it can be classified as part of the SHT family. With reflection mode, the heat conduction from surface to inside is used to quantify the depth of defect.

MWT exhibits volumetric heating for dielectric material inspection. MWT can be called volume heating thermography (VHT), as illustrated in Figure $4 \mathrm{~b}$ [45,55]. For the transmission and reflection modes with VHT, the characterizations of defects are similar [54]. Only interesting areas are heated without heating the host material in some cases. Abnormal heat will caused by defects. Furthermore, this abnormal heat is used to quantify depth information of the related defect. In Figure 4c, these methods are called abnormal heating thermography (AHT). For detecting water in concrete structures, MWT can be considered as a kind of AHT.

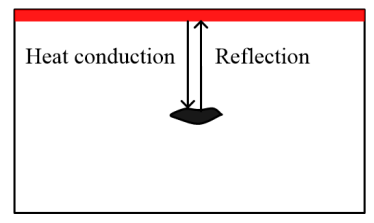

(a)

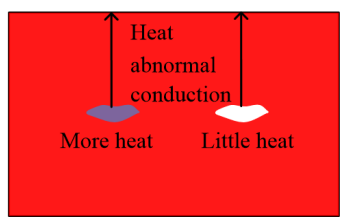

(b)

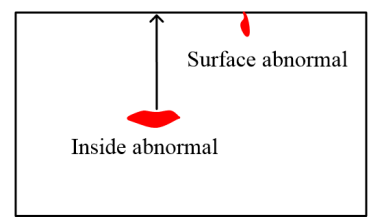

(c)

Figure 4. Styles of heating: (a) SHT; (b) VHT; (c) AHT.

\section{Developments and Case Studies}

\subsection{A History of MWT Development}

Developed countries have taken the lead on the use of MWT to carry out related researches and achieved some interesting results [56-58]. Levesque and Ambrosio did a preliminary study on MWT in the 1990s. Levesque et al. employed X and Ku bands (range from $8 \mathrm{GHz}$ to $18 \mathrm{GHz}$ ) horns and parabolic antennas to excite the sample under test [59]. The excitation of the antenna is provided by a $100 \mathrm{~W}$ amplifier. Thermal images are produced by an AGEMA (model 782 LWB) IR camera with $8 \mu \mathrm{m}-12 \mu \mathrm{m}$ range. An area of $300 \times 300 \mathrm{~mm}^{2}$ is been measured due to the limited excitation area. Several $10 \mathrm{~mm}$ thick glass-epoxy composites have been tested to identify the inserted carbon particles area. The proposed method were used to characterize artificial defects' size and location under different depths in composite materials. Ambrosio et al. used a cavity with a minimum $600 \mathrm{~W}$ to detect artificial defects in non-metallic composites [60]. The cavity was $300 \times 200 \times 280 \mathrm{~mm}^{3}$ which is excited by a $2.45 \mathrm{GHz}$ magnetron and an Alter VPG1540 power supply unit (maximum power $1200 \mathrm{~W}$ ). They used a Cober PM45 power meter to monitor the incident and reflected microwave powers. Two cavity applicators (an open cavity applicator and a large cavity applicator) have been proposed to avoid the aperture edge effects and to improve the field uniformity over the sample. To estimate the defect permittivity and depth influence on surface temperature perturbation, theoretical modeling and numerical simulations were carried out.

In 1999, Takahide et al. at Osaka University applied MWT to detect surface breaking cracks in reinforced concrete structures and they pointed out that the tip of crack will produce more heat during the test [61]. Heat was introduced by a time-gated microwave source into the homogeneously reinforced concrete structure. With the microwave penetration features, the subsurface of the reinforced concrete structure could be inspected. Moreover, wet cracks could be selectively heated. Therefore, subsurface cracks will be immediately identified with MWT. Analyses of time and spatial dependence features of measured thermal images are possible to quantify cracks' depth and thermal diffusivity information [61]. In the 21st century, groups in the USA, UK, France, Poland, Italy, Korea, etc. have developed MWT for metal, dielectric material, cement/concrete, GFRP, CFRP, honeycomb and cement-based composites detection problems. These works have been simply summarized in Table 2 and are introduced in detail in the following Sections 4.2-4.9. 
Table 2. Summary of researches with MWT.

\begin{tabular}{|c|c|c|c|c|c|c|c|c|}
\hline \multicolumn{4}{|c|}{ Hardware Development } & \multicolumn{3}{|c|}{ Software Development } & \multicolumn{2}{|c|}{ Experimental Study } \\
\hline $\begin{array}{l}\text { Operation } \\
\text { Frequency }\end{array}$ & Antenna/Sensor & Power & IR Camera & Simulation Study & Sampling Software & Signal Processing & Material under Test & Defects \\
\hline $\begin{array}{l}8 \mathrm{GHz} \text { to } \\
18 \mathrm{GHz}[59]\end{array}$ & $\begin{array}{l}\text { Horns and parabolic } \\
\text { antennas [59] }\end{array}$ & $100 \mathrm{~W}$ [59] & $\begin{array}{l}\text { AGEMA 782 } \\
\text { LWB [59] }\end{array}$ & Not available & $\begin{array}{l}\text { CEDIP PTR-9010 } \\
\text { system [59] }\end{array}$ & $\begin{array}{l}\text { Normalized the infrared images } \\
\text { pixel by pixel [59] }\end{array}$ & $\begin{array}{c}\text { Glass-epoxy } \\
\text { composites [59] }\end{array}$ & Delaminations \\
\hline \multirow[t]{2}{*}{$2.45 \mathrm{GHz}[60,61]$} & Magnetron [60] & $600 \mathrm{~W}-1700 \mathrm{~W}$ [60] & $\begin{array}{l}\text { AGEMA AGA } \\
\quad 880[60]\end{array}$ & $\begin{array}{c}\text { Influence of defect } \\
\text { permittivity and depth } \\
\text { has been estimated [60]. }\end{array}$ & $\begin{array}{l}\text { HP } 8757 \text { C network } \\
\text { analyzer [60] }\end{array}$ & $\begin{array}{l}\text { Open cavity applicator and large } \\
\text { cavity applicator have been } \\
\text { designed [60] }\end{array}$ & $\begin{array}{l}\text { Kevlar or fiberglass slabs } \\
\text { and sandwich } \\
\text { samples [60] }\end{array}$ & Defects \\
\hline & Microwave oven [61] & $1400 \mathrm{~W}$ [61] & Nikon LAIRD-3 [61] & Not available & Not available & $\begin{array}{c}\text { Thermal image } \\
\text { was taken at 20 s [61] }\end{array}$ & Mortar block [61] & Cracks \\
\hline $\begin{array}{l}2 \mathrm{GHz} \text { to } 3 \mathrm{GHz}[62], \\
2.45 \mathrm{GHz}[63,64]\end{array}$ & $\begin{array}{c}\text { TEM horn } \\
\text { antenna }[62,64]\end{array}$ & $\begin{array}{c}50 \mathrm{~W}[62,64] \\
10 \mathrm{~W}[63]\end{array}$ & $\begin{array}{c}\text { DRS Tamarisk } 320 \\
\text { [62,64], FLIR SC } \\
500[63]\end{array}$ & $\begin{array}{l}\text { CST Microwave Studio } \\
\text { and MPHYSICS } \\
\text { Studio [62]. }\end{array}$ & Not available & $\begin{array}{l}\text { The surface thermal profile was } \\
\text { taken after } 10 \mathrm{~s} \text { of heating [62]. } \\
\text { The surface thermal profile was } \\
\text { taken after } 5 \mathrm{~s} \\
\text { and } 15 \mathrm{~s} \text { of heating [63]. }\end{array}$ & \multirow{2}{*}{$\begin{array}{c}\text { Reinforced steel bars [62], } \\
\text { Rebar in air [63]; } \\
\text { Embedded in cement } \\
\text { [63,65], CFRP [64] }\end{array}$} & $\begin{array}{l}\text { Corrosion, delaminations, } \\
\text { debonding and crack }\end{array}$ \\
\hline $2.45 \mathrm{GHz}[65]$ & $\begin{array}{l}\text { Magnetron generated } \\
\text { horn antenna [65] }\end{array}$ & $600 \mathrm{~W}[65]$ & Not available & Not available & ALTAIR software & $\begin{array}{l}\text { A contrast algorithm is used to } \\
\text { analyze the thermogram series } \\
\text { with } 5 \text { min of heating [65]. }\end{array}$ & & Steel bar corrosion \\
\hline $5 \mathrm{GHz}$ to $10 \mathrm{GHz}$ [66] & Horn antenna [66] & \multirow{2}{*}{$2.3 \mathrm{~W}[66,67]$} & $\begin{array}{c}\text { Mikron 6T61 and } \\
\text { SantaBarbara IR } \\
\text { camera [66] }\end{array}$ & Not available & $\begin{array}{c}\text { Macintosh } \\
\text { microcompute [66] }\end{array}$ & $\begin{array}{l}\text { A } 2.7 \text { s microwave } \\
\text { pulse was used [66] }\end{array}$ & $\begin{array}{c}\text { Multilayered } \\
\text { plexiglass-water-teflon } \\
\text { specimen [66] }\end{array}$ & Debonding \\
\hline $9 \mathrm{GHz}$ [67] & $\begin{array}{l}\text { A single flare horn } \\
\text { antenna [67] }\end{array}$ & & $\begin{array}{l}\text { Santa Barbara } \\
\text { Focalplane [67] }\end{array}$ & Not available & LabVIEW & $\begin{array}{c}\text { The surface thermal profile was } \\
\text { taken after } 8 \mathrm{~s} \\
\text { and } 10 \mathrm{~s} \text { of heating [67] }\end{array}$ & $\begin{array}{l}\text { Carbon fibers in different } \\
\text { epoxy structures [67] }\end{array}$ & Embedded fibers \\
\hline $18 \mathrm{GHz}[57]$ & $\begin{array}{l}\text { Flann } 18 \text { 094-SF40 } \\
\text { waveguide [57] }\end{array}$ & $1 \mathrm{~W}[57]$ & FLIR SC7500 [57] & \multirow{2}{*}{$\begin{array}{l}\text { COMSOL Multiphysics } \\
\text { and CST Microwave } \\
\text { Studio [57] }\end{array}$} & $\begin{array}{l}\text { Rohde \& Schwarz } \\
\text { SMF 100 A signal } \\
\text { generator [57] }\end{array}$ & $\begin{array}{l}\text { The surface thermal profile was } \\
\text { taken after } 10 \text { min of heating [57] }\end{array}$ & \multirow{2}{*}{ GFRP [57] } & Defects \\
\hline \multirow{3}{*}{$2.45 \mathrm{GHz}[56,68]$} & WR430 waveguide [57] & $1000 \mathrm{~W}$ [57] & \multirow{2}{*}{ Flir A325 $[57,68]$} & & \multirow[b]{2}{*}{ Not available } & $\begin{array}{l}\text { The surface thermal profile was } \\
\text { obtained after } 10 \mathrm{~s} \text { to } 15 \mathrm{~s} \text { of } \\
\text { heating [57] }\end{array}$ & & $\begin{array}{c}\text { Debonding and } \\
\text { delamination }\end{array}$ \\
\hline & Magnetron [68] & $500 \mathrm{~W}[68]$ & & Not available & & $\begin{array}{l}\text { A sequence of } 180 \text { thermograms } \\
\text { was obtained and processed by } \\
\text { using normalized, standardized } \\
\text { contrast and cosine transform [68] }\end{array}$ & $\begin{array}{l}\text { Composite materials with } \\
\text { adhesive bounded } \\
\text { joints [68] }\end{array}$ & Defects \\
\hline & $\begin{array}{c}\text { Pyramidal horn } \\
\text { antenna [56] }\end{array}$ & $360 \mathrm{~W}[56]$ & Not available & Not available & $\begin{array}{c}\text { ALTAIR } \\
\text { program [56] }\end{array}$ & $\begin{array}{l}\text { The surface thermal profile was } \\
\text { taken after } 150 \text { s of heating [56] }\end{array}$ & CFRP [56] & Defects \\
\hline $1 \mathrm{GHz}[69]$ & $\begin{array}{l}\text { Coaxial-type } \\
\text { probes [69] }\end{array}$ & $0.1 \mathrm{~W}[69]$ & FLIR T620 [69] & $\begin{array}{l}\text { CST Microwave } \\
\text { Studio [69] }\end{array}$ & Spectrometer [69] & $\begin{array}{c}\text { Normalized to the maximum } \\
\text { value of field intensity [69] }\end{array}$ & $\begin{array}{l}\text { Carbon-fiber composite } \\
\text { materials [69] }\end{array}$ & $\begin{array}{l}\text { Conductivity } \\
\text { measurement }\end{array}$ \\
\hline
\end{tabular}




\subsection{Metals and Corrosion}

Foudazi et al. from the Missouri University of Science and Technology proposed the use of MWT for the detection and characterization of corroded reinforced steel bars [62]. In Figure 5a, the measurement setup for steel bars is illustrated. They employed a $14 \times 24 \mathrm{~cm}^{2}$ horn antenna to irradiate steel bars with a $50 \mathrm{~W}$ microwave signal for $10 \mathrm{~s}$. The distance between the steel bars and the antenna was $1 \mathrm{~cm}$. During the experiment, four pieces of corroded material were mounted on steel bars and spaced $1 \mathrm{~cm}$ apart. A DRS Tamarisk 320 thermal camera was utilized to obtain the thermal profile of the steel bars with a $0.05 \mathrm{~K}$ sensitivity. In Figure $5 \mathrm{~b}$, the surface thermal profiles for steel bars after $10 \mathrm{~s}$ as detected with $2 \mathrm{GHz}, 2.5 \mathrm{GHz}$, and $3 \mathrm{GHz}$ energy are provided. The steel bars were a smooth rebar without ribs. The radius of this rebar was $4.8 \mathrm{~cm}$ which contained a $1 \mathrm{~cm}$ corrosion area. In Figure 5b, the visible hot spots are the corroded areas on these steel bars. Because of the relatively low thermal conductivity of corroded steel, heat quickly dissipates in uncorroded steel. Moreover, these temperature differences between the corroded areas indicated that different amounts of corrosion absorb different amounts of microwave energy. With a preliminary simulation and experimental study of the MWT, it demonstrated that a higher excitation microwave frequency will lead to a higher temperature for corrosion detection in steel bars. Moreover, increased corrosion leads to absorption of microwave energy increasing results in a greater difference in the measured IR images.
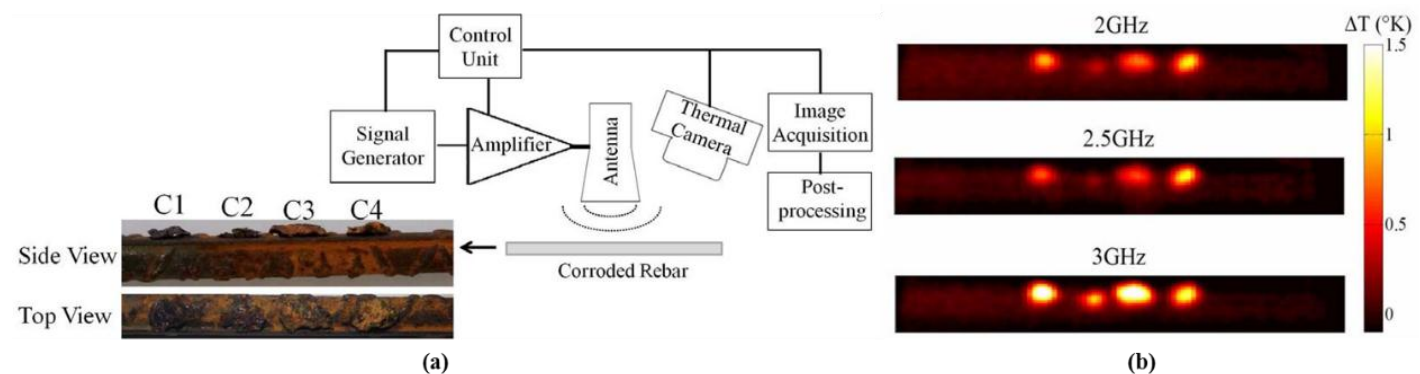

(b)

Figure 5. (a) MWT measurement setup for corroded rebar detection; (b) temperature profile for corroded steel bar [62]. Reprinted/reproduced with permission from IEEE. .

Pieper et al. demonstrated an active MWT for inspection of large corrosion areas on reinforcing steel bars for cement-based structures [63]. They used CST Microwave studio and MultiPhysics studio to construct a coupled microwave and thermal simulation model. The effects of steel bars have been investigated in the air and in concrete. To detect the change in temperature with a thermal camera, the incident microwave power should be increased because some of the microwave energy is absorbed by the concrete. The effect of different polarization has been studied with CST. With $10 \mathrm{~W}$ incident power, the parallel polarization generates the most uniform heating in that of orthogonal polarization and circular polarization, but the temperature increase was the lowest (only $0.014{ }^{\circ} \mathrm{C}$ ). The highest temperature increase was generated by orthogonal polarization (around $0.025^{\circ} \mathrm{C}$ ), therefore, orthogonal polarization is the best choice for thin corrosion detection.

During the experimental study, two steel (AISI 1008) bars (each of length $150 \mathrm{~mm}$ and radius $4.8 \mathrm{~mm}$ ) were measured, which have been embedded in parallel in a concrete block $\left(170 \times 150 \times 50 \mathrm{~mm}^{3}\right)$. The sample was heated for $5 \mathrm{~s}$ by a microwave oven operating at $2.45 \mathrm{GHz}$. A FLIR Thermacam SC 500 was used to provide thermal images with a sensitivity of $0.1{ }^{\circ} \mathrm{C}$. In Figure $6 \mathrm{a}$, the two steel bars have been heated by microwave energy for $15 \mathrm{~s}$. One (top) with localized significant corrosion (on the order of $1 \mathrm{~mm}-4 \mathrm{~mm}$ ) on a portion of its length, the one below with light corrosion (on the order $0.2 \mathrm{~mm}$ or less) along half of its length. As illustrated in Figure $6 \mathrm{~b}, \mathrm{c}$, the corroded areas in the two steel bars have been identified in the thermal images as indicated by the black circle. Moreover, in Figure $6 c$, the uncorroded area in the steel bar is also visible, appearing as a relatively 
lower temperature line (in the left of the black circle). In Figure 6e, the corroded steel bar is still detectable when embedded in a concrete block as highlighted by the black circle. These results show that steel corrosion in concrete will lead to a higher loss tangent and the thermal properties are changed. With microwave heating, the physical property changes due to corrosion become measurable in the thermograms. Depending on the orientation and thickness of corrosion, the polarization of the incident microwave signal can be optimized through simulation. The effect of corrosion layer thickness on microwave heating has been investigated.

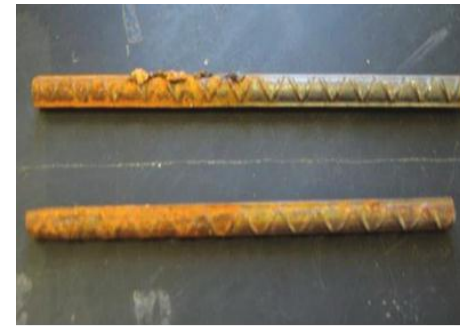

(a)

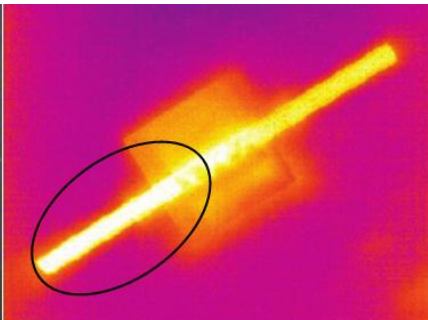

(b)

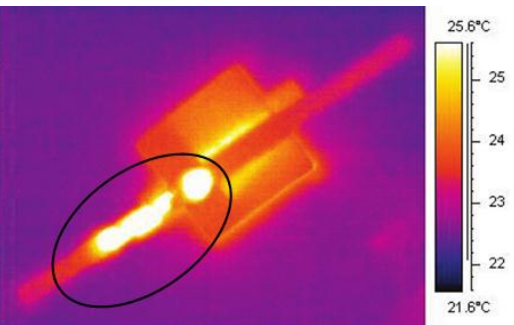

(c)

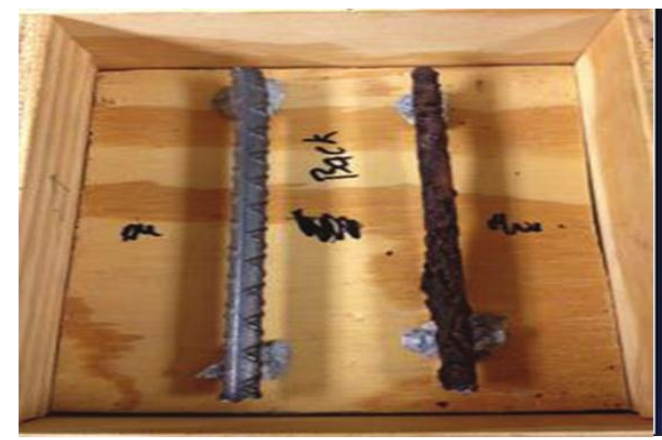

(d)

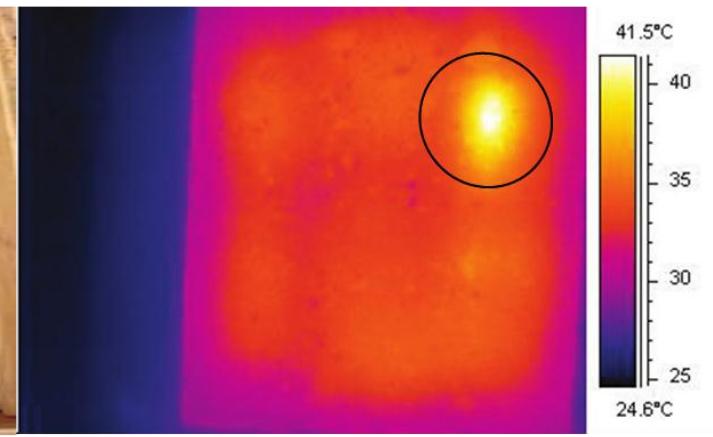

(e)

Figure 6. (a) Photograph of localized corrosion (top) and light corrosion (bottom); (b) thermal images of a steel bar with light corrosion and (c) localized corrosion; (d) photograph of clean (left) and corroded (right) steel bars; (e) thermal images of clean (left) and corroded (right) steel bars embedded in the concrete block after microwave heating [63]. Reprinted/Reproduced with permission from AIP Publishing LLC.

Keo et al. presented a pyramidal horn antenna based MWT to detect corroded steel in a reinforced concrete wall [65]. During the experimental study, a commercial magnetron operating at $2.45 \mathrm{GHz}$ was used to irradiate a maximum $800 \mathrm{~W}$ of microwave energy. The steel reinforcements (each one with a diameter of $12 \mathrm{~mm}$, located at a regular spacing of $10 \mathrm{~cm}$ ) with a $38 \mathrm{~mm}$ concrete covering were embedded in a concrete block $\left(1000 \times 1000 \times 65 \mathrm{~mm}^{3}\right)$. The specimen was heated by $600 \mathrm{~W}$ microwave energy for $5 \mathrm{~min}$. The reflection mode was used as the thermal camera was placed on the same side as the excitation source. A data analysis method based on a contrast algorithm was used to analyze the thermogram series to reduce the effect of non-uniform excitation. As shown in Figure 7a, the infrared camera was composed of a $320 \times 256$ matrix detector of indium antimonide (InSb) with a sensitivity range of 3-5 $\mu \mathrm{m}$. The excitation antenna was placed in a $45^{\circ}$ direction to heat the largest surface area of the specimen. In addition, the infrared camera was placed at $2.32 \mathrm{~m}$ away from the specimen in a $30^{\circ}$ direction which can detect the largest possible surface area of the specimen. Thermograms were recorded at 1 image per s by using the ALTAIR software (developed by FLIR for obtaining measurement data). Figure $7 \mathrm{~b}$ shows the obtained thermograms at the $250 \mathrm{~s}$ instant. The abnormal temperature areas correspond to the corrosion area in the steel reinforcements. In the preliminary experimental study of the MWT, it was demonstrated that the detection depth of MWT was about $3.8 \mathrm{~cm}$ in a thick concrete block. 


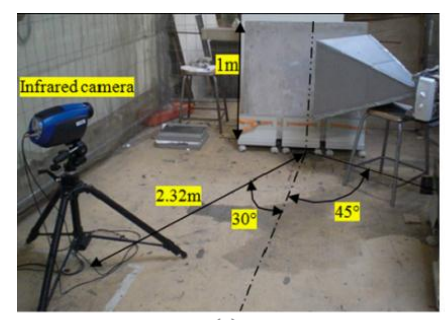

(a)

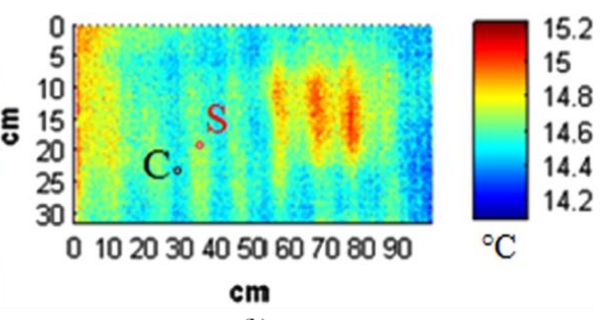

(b)

Figure 7. Photograph of microwave thermography measurement setup (a) and temperature profile for corroded steel bar (b) [65]. Reprinted/reproduced with permission from Elsevier.

\subsection{Dielectric Materials}

Osiander et al. employed a time-resolved MWT system for surface and sub-surface inspection on Plexiglass-water-Teflon specimens with absorbers at different depths $(0.15,0.30$ and $0.45 \mathrm{~mm})$ [66]. Figure 8a shows a diagram of the experimental setup. An HP 6890B oscillator was used to generate microwave pulses with a frequency range from $5 \mathrm{GHz}$ to $10 \mathrm{GHz}$. A Hughes $1277 \mathrm{X}$-band traveling wave tube amplifier with $2.3 \mathrm{~W}$ maximum power was utilized as a power amplifier. An excitation horn antenna was placed in a $45^{\circ}$ direction with respect to the sample surface. Two infrared cameras were used to monitor the surface temperature of the sample under test. One was a Mikron 6T61 infrared scanner with an HgCdTe detector. The second one was a SantaBarbara infrared camera with a $128 \times 128$ pixels InSb focal plane array. The temperature resolution of the first camera was $0.1 \mathrm{~K}$. For the second IR camera, the temperature resolution is about $0.003 \mathrm{~K}$. The specimen under test is illustrated in Figure $8 \mathrm{~b}$. It is structured with a Teflon layer of varied thickness and a water layer with a constant thickness backed with Plexiglass layers. Considering the power, the microwave horn was working in the near field. The measured data was normalized to the peak amplitude to eliminate the effects of non-uniform microwave distribution. Figure $8 \mathrm{c}$ shows IR images of the test sample before, during and after a $2.7 \mathrm{~s}$ microwave pulse. Three water layers corresponding to the Teflon layer thicknesses appear in the IR images in a temporal order. With MWT, the potential of surface temperature versus time has been shown for subsurface defects quantitative characterization. Compared with laser beam heating, dry epoxy coated steel samples exhibit a very small response with microwave heating. When a debonding region contains water, the whole structure of the debonding region can be illustrated. The wavelength independent resolution has been demonstrated to be $30 \mu \mathrm{m}$. An analytical model has been provided to extract the time dependence of the surface temperature where quantitative data such as the depth of the defect can be extracted.

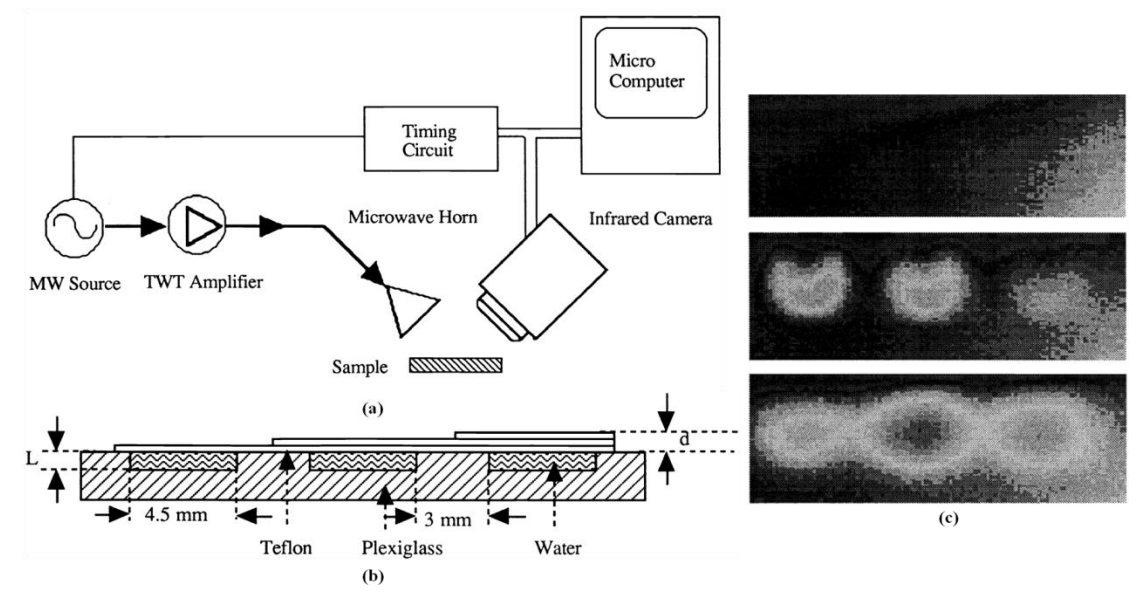

Figure 8. Schematic diagram of the experimental setup (a), the specimen under test (b) and IR images (c) [66]. Reprinted/reproduced with permission from SPIE. 


\subsection{Cement and Concrete}

Takahide et al. proposed the use of MWT for detecting surface-breaking cracks in concrete [61]. Surface-breaking cracks can be penetrated with water. The crack opening distance was $0.2 \mathrm{~mm}$ and $0.4 \mathrm{~mm}$. The size of the cracks was $10 \mathrm{~mm}$ in depth and $40 \mathrm{~mm}$ in width. Since the microwave absorptivity of the concrete is much smaller than that of water, cracks containing water can be selectively heated. By applying microwaves to the concrete structure, the thermal conduction of these heated cracks will generate localized high-temperature regions. The experimental MWT setup is illustrated in Figure 9a. A commercially available $2.45 \mathrm{GHz}$ magnetron was used to irradiate microwaves into the mortar block with a maximum $1400 \mathrm{~W}$ output power. The specimen under test was placed in the microwave oven. A Nikon LAIRD-3 with PtSi array was used to measure the temperature distribution of the mortar block. In Figure 9b, four artificial cracks have been introduced to a rapid hardening mortar block specimen. By injecting water into crack $C$ and applying microwaves for $5 \mathrm{~s}$, crack $\mathrm{C}$ with water was selectively heated. Compared with the non-crack area, the temperature of the crack rose about $6{ }^{\circ} \mathrm{C}$ to $8{ }^{\circ} \mathrm{C}$ after microwave heating. As shown in Figure $9 \mathrm{c}$, the position of the crack $C$ can be easily detected from the thermal image taken immediately after the microwave excitation. Meanwhile, the authors found that the temperature region of the crack degraded after $20 \mathrm{~s}$ due to the thermal diffusion from the crack into the surrounding area. The relation between the crack size and temperature rise should be determined for quantitative investigations.

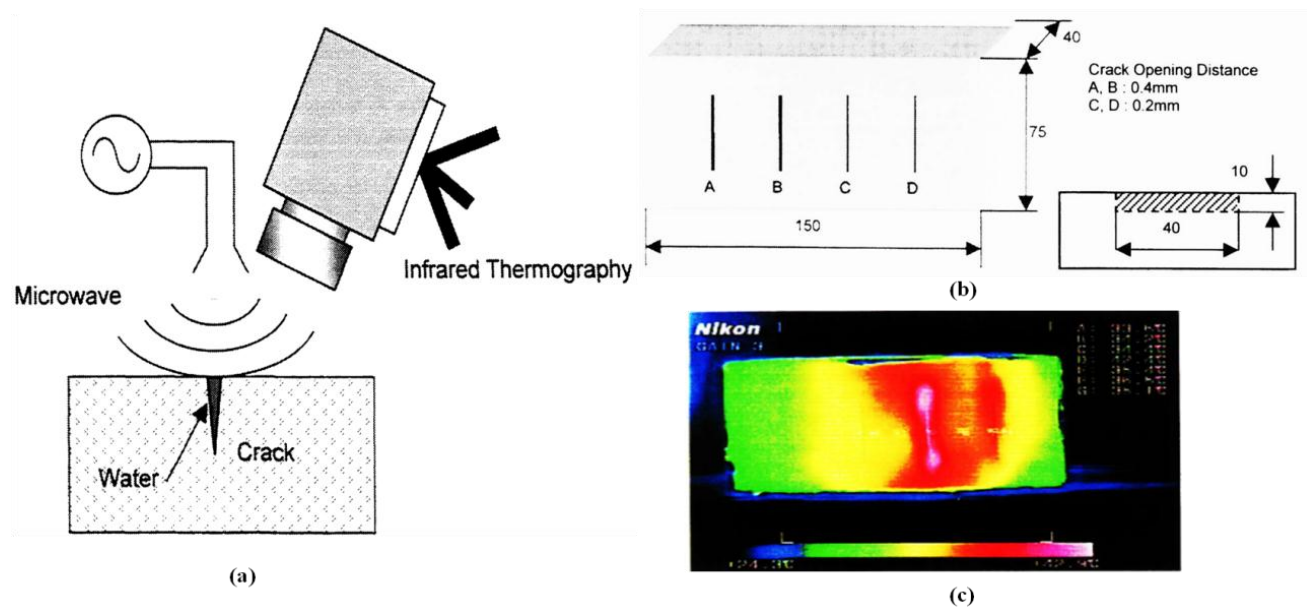

Figure 9. Schematic diagram of MWT (a), mortar block specimen with artificial cracks (b) and thermal images taken after microwave heating (c) [61]. Reprinted/reproduced with permission from SPIE.

\subsection{Glass Fiber Composite Structures}

Bowen et al. introduced microwave-source time-resolved infrared radiometry for detecting and characterizing microwave absorption in dielectric materials [67]. An HP 6890B oscillator was used to excite a $9 \mathrm{GHz}$ microwave signal. A Hughes $1277 \mathrm{X}$-band traveling wave tube amplifier was used to amplify this signal to a maximum $2.3 \mathrm{~W}$ power. A single flare horn antenna with about $50^{\circ}$ beam width was placed $15 \mathrm{~cm}$ from the sample under test. A Santa Barbara camera with $128 \times 128 \mathrm{InSb}$ focal plane array was used to detect the IR radiation. The temperature resolution is about $0.003 \mathrm{~K}$. With embedded fibers at different locations, a fiberglass-epoxy specimen was measured. The depth of the fibers was $0.25 \mathrm{~mm}$ and $0.75 \mathrm{~mm}$. Due to the loss tangent and Joule heating, there is a very high contrast for defects in embedded epoxy materials. The size and orientation of these embedded fibers in the measured thermal images have been studied. The interaction is strongly dependent on the length of the fiber ( $9 \mathrm{~mm}$ to $30 \mathrm{~mm}$ ) and orientations. The temperature shows a modal distribution along the fiber for fibers longer than $12 \mathrm{~mm}$. 
Cheng et al. [57] developed a microwave pulsed thermography system for glass fiber composite measurement. Figure 10a illustrates the setup of the experimental system: (1) an adaptor connected with the waveguide; (2) GFRP wind turbine blade; (3) microwave generator linked with cable; (4) IR camera. GFRP wind turbine blade with 4 holes ( $4.5 \mathrm{~mm}$ in radius) at the root was heated by an open-ended waveguide connected with a Flann 18 094-SF40 adaptor. The adaptor was linked to a signal generator (Rohde \& Schwarz SMF $100 \mathrm{~A}$ ) with the maximum output power of $30 \mathrm{dBm}$ $(1 \mathrm{~W})$ at $18 \mathrm{GHz}$. The waveguide was placed above the sample with roughly a 45 degree illumination direction. A FLIR SC7500 IR camera was used to obtain the temperature distribution. Artificial holes with $4.5 \mathrm{~mm}$ radius were investigated. During the experiment, the signal generator provided $1 \mathrm{~W}$ microwave power, although only $115.2 \mathrm{~mW}$ microwave power was emitted from the waveguide due to the cable loss. In order to maximize the actual illumination power and minimize the power loss during the transmission, $22.7 \mathrm{~mm}$ was selected as the standoff distance (distance between the microwave antenna aperture and sample under test) due to the impedance matching (this distance should be around $\lambda / 4$ to maximum power transfer, where $\lambda$ is the wavelength of microwave). In their primary experimental results, a discontinuous temperature was captured in the defect region (mainly at the edges). A high power heating system is required for a better contrast of heat patterns between defect and non-defect regions.



Figure 10. MWT setup in Newcastle University (a) and West Pomeranian University of Technology (b) [57]. Reprinted/reproduced with permission from IEEE.

A magnetron-based microwave pulsed thermography system has been developed by West Pomeranian University of Technology for glass fiber composite debonding and delamination detection [57]. A GFRP wind turbine blade (BLADES200W from Navitron) with a $4.5 \mathrm{~mm}$ hole at the middle was the study object. Figure $10 \mathrm{~b}$ illustrates system setup for high power microwave pulsed thermography. With a maximum $1 \mathrm{~kW}$ power, the microwave excitation was a $2.45 \mathrm{GHz}$ magnetron. An open-ended aperture was matched impedance with a WR-430 waveguide. Dipolar Magdrive 1000 was used to control the output power. A Flir A325 device was used to obtain thermograms. A $0.238^{\circ} \mathrm{C}$ 
maximum temperature raise can be obtained from $2 \mathrm{~s}$ heating. In their primary experiment results, the location and the size information of the defect have been detected from the continuities in the line-scan results.

Ryszard et al. also employed MWT for inspecting adhesive joints in composite materials [68]. Due to the dielectric property differences between defects (lack of adhesive or delamination) and the background, the induced thermal energy in the defect region and the background in the material under test is different. The experimental setup is illustrated in Figure 11a: (1) an IR camera in a protective box to prevent damage caused by the high power microwaves; (2) a $500 \mathrm{~W}$ magnetron working at $2.45 \mathrm{GHz}$; (3) microwave absorbers; (4) an open-ended rectangular waveguide; (5) the sample under test; (6) a cooling system for the magnetron. The MWT observation time was set to $180 \mathrm{~s}$ to obtain 180 thermograms in one sequence. The measured results were obtained by using dedicated image processing algorithms. As shown in Figure 11b-e, the original thermogram (b), cosine transform (c), standardized contrast (d) and contrast enhancement (e) were used to obtain images of the defect. In the primary experiment results, approximate location and the size information about delamination can be obtained in the thermograms after processing.

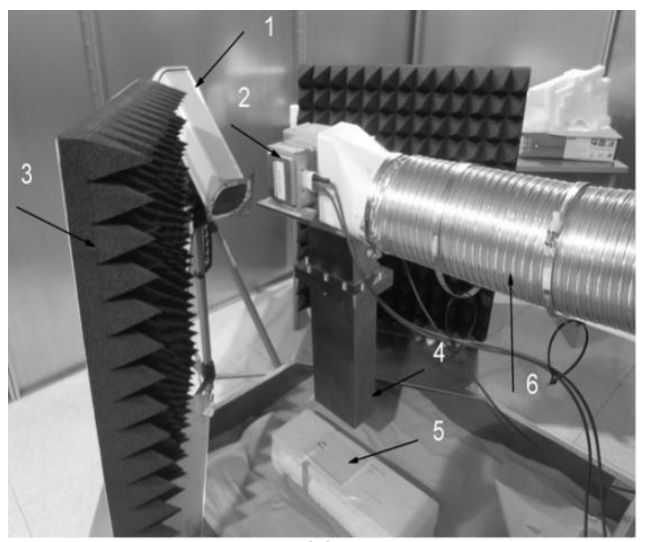

(a)

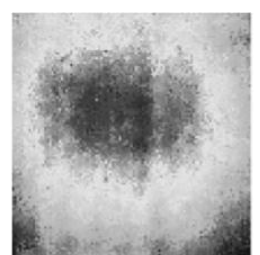

(b)

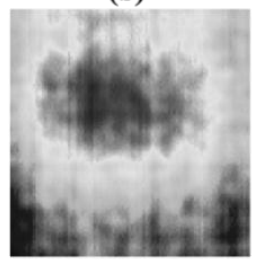

(d)

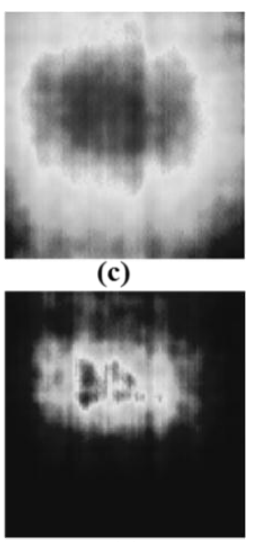

(e)

Figure 11. Experimental setup for MWT (a) and measurement results (b-e) [68]. Reprinted/reproduced with permission from authors.

We also investigated MWT for defect detection in a glass fiber wind turbine blade, as shown in Figure 12. A horn antenna (ETS Lindgren 3115, frequency range: $750 \mathrm{MHz}-18 \mathrm{GHz}$.) was used for microwave excitation. The antenna was connected to Rohde \& Schwarz SMF 100 A signal generator with a maximum output power of $1 \mathrm{~W}$. The waveguide was placed above the sample with roughly 90 degree illumination direction. A FLIR SC7500 IR camera was used to obtain the temperature distribution of sample under test. During the experiment, the signal generator provided $1 \mathrm{~W}$ at $0.915 \mathrm{GHz}$ and $2.45 \mathrm{GHz}$. In order to detect defects during the experiment, the microwave heating duration was selected as $1 \mathrm{~min}$ (as shown in Figure 13a,c) and $2 \mathrm{~min}$ (as shown in Figure 13b,d). In our initial experiment results, a discontinuous temperature was captured in the defect region. Furthermore, the heating effect of $2.4 \mathrm{GHz}$ is not as good as $0.915 \mathrm{GHz}$ due to the penetration ability difference. With the captured IR images, defects around $1 \mathrm{~mm}$ radius with $0.2 \mathrm{~mm}$ in depth could be obtained in the GFRP sample. With a longer heating duration, the number of defects became hard to identify due to the heat diffusion, therefore, the heating time must be optimized for different situations. 


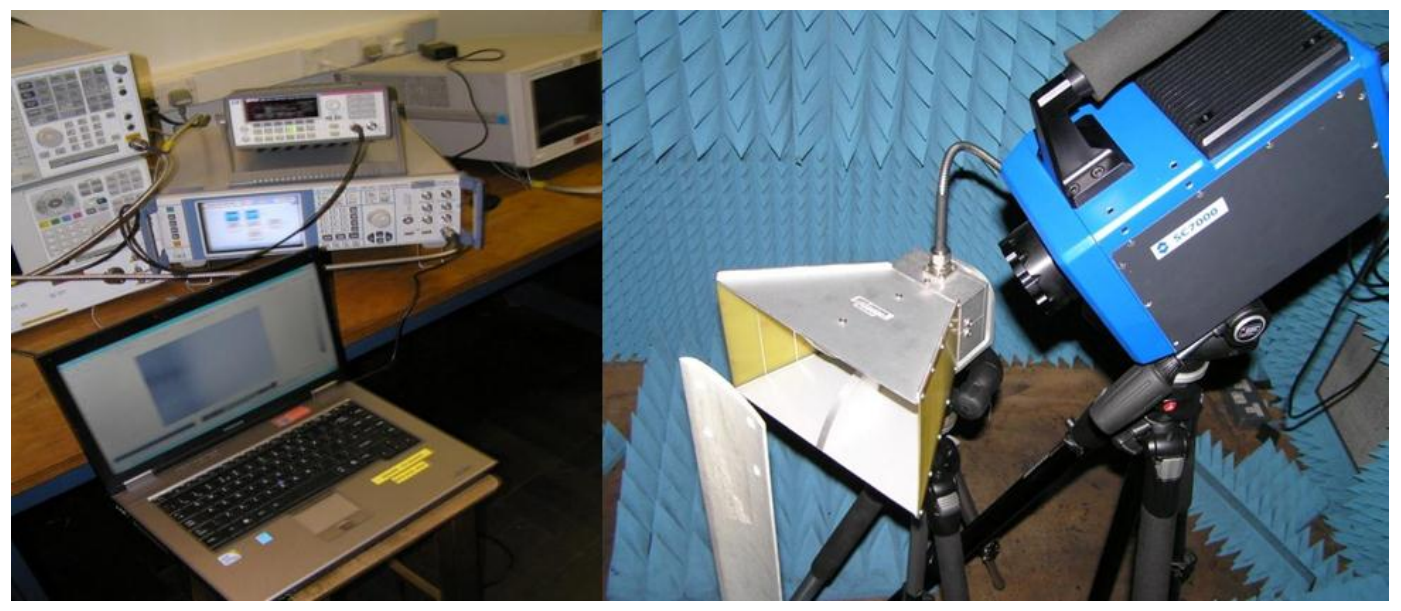

Figure 12. Experimental setup for defect detection with MWT.
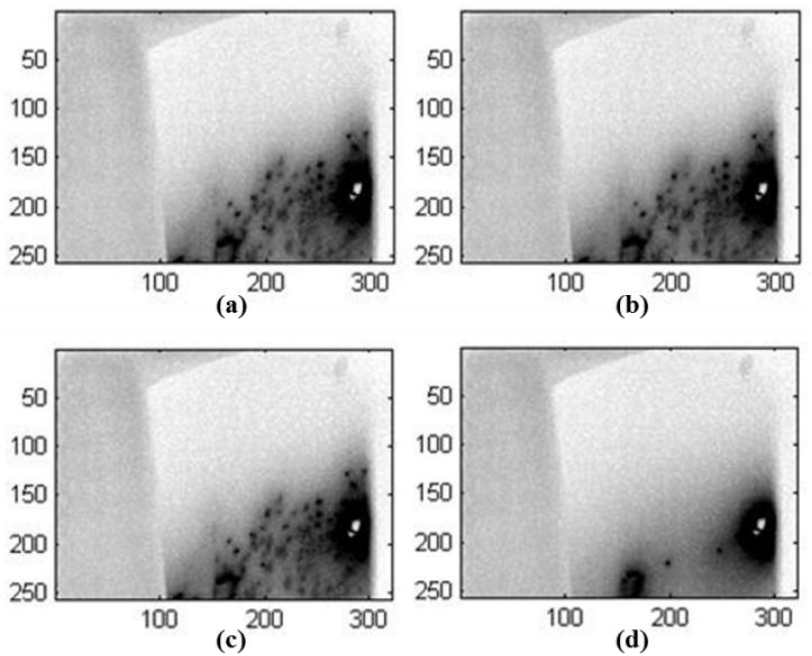

Figure 13. IR results with MWT for defect detection in glass fiber wind blade after 1 min microwave excitation with $0.915 \mathrm{GHz}$ (a), after 2 min microwave excitation with $0.915 \mathrm{GHz}$ (b), after $1 \mathrm{~min}$ microwave excitation with $2.45 \mathrm{GHz}$ (c) and after 2 min microwave excitation with $2.45 \mathrm{GHz}(\mathrm{d})$.

\subsection{Carbon Fiber Composite Materials}

In France, Keo et al. developed a microwave pulsed thermography for CFRP detection [56]. They used a commercial $2.45 \mathrm{GHz}$ magnetron to generate microwave signals. With a detector with a $320 \times 256 \mathrm{InSb}$ matrix, the sensitivity of the IR camera is in a range of $3 \mu \mathrm{m}-5 \mu \mathrm{m}$. To capture the whole inspection area, the sample was placed $1.5 \mathrm{~m}$ away from IR camera at $55^{\circ}$. The CFRP sample was $40 \times 40 \times 4.5 \mathrm{~cm}^{3}$. A $10 \times 10 \mathrm{~cm}^{2}$ defect was created at the middle of the CFRP sample by the absence of adhesive. The antenna was placed in the $45^{\circ}$ direction as shown in Figure 14a. In Figure 14b, the microwave beam was guided by a $59 \times 56 \mathrm{~cm}^{2}$ pyramidal horn antenna onto the sample under test. With the ALTAIR program provided by FLIR, a computer was used to record thermograms at $1 \mathrm{~Hz}$. A $360 \mathrm{~W}$ microwave was used to heat the specimen for $150 \mathrm{~s}$. The same testing procedure was carried out on samples with/without defect. As shown in Figure 15, the thermograms at the $100 \mathrm{~s}$ were obtained. In Figure 15a, a non-defect specimen has been shown in the thermogram at the 100 $\mathrm{s}$ instant. In Figure 15b, a specimen with a defect has been shown in the thermogram. In Figure 15c, the thermogram of the sample with a defect (Figure 15a) has been subtracted with the thermogram of the sample without defect (Figure 15b) at the same instant. In Figure 15d, the thermogram in Figure 15c is subtracted from its initial thermogram in order to highlight the defect. In the primary experiment 
results, the CFRP defect area can be clearly found. It is hotter than the non-defect area due to the absence of adhesive. The defect area can be estimated directly from the thermograms (about $10 \times 10 \mathrm{~cm}^{2}$ ) [56].

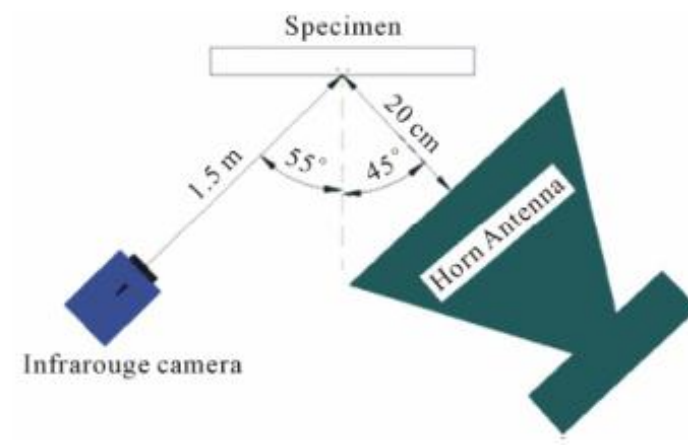

(a)
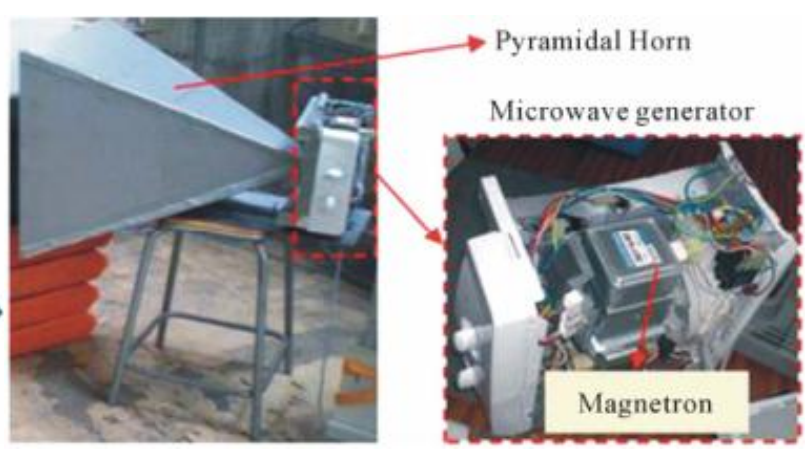

(b)

Figure 14. MWT setup (a) and Horn (b) in University Institute of Technology of Bethune [56]. Reprinted/reproduced with permission from Scientific Research Publishing Inc.

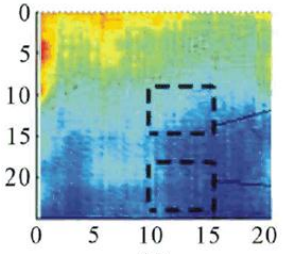

(a)

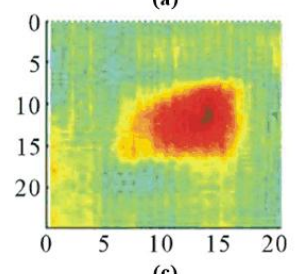

(c)

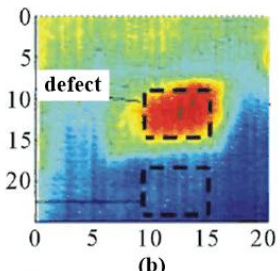

(b)

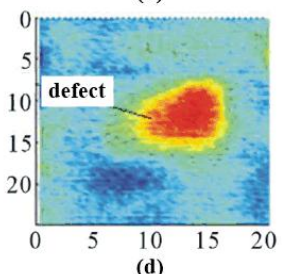

(d)

Figure 15. MWT results for the absence of adhesive in CFRP: the thermogram of the sample without defect (a), the thermogram of the sample with the defect (b), the subtraction between the thermograms of the sample with and without the defect (c), thermogram subtracted from its initial thermogram (d) [56]. Reprinted/reproduced with permission from Scientific Research Publishing Inc.

In 2014, Foudazi et al. investigated MWT for the inspection of rehabilitated cement-based structures [64]. The experimental setup is shown in Figure 16a,b, $2.4 \mathrm{GHz}$ microwaves have been transmitted with $50 \mathrm{~W}$ power. A sweep oscillator (HP8690B) and a power amplifier (OphirRF 5303084) are used to generate high power microwave signals. The sample under test was illuminated by a horn antenna. With a sensitivity of $0.05 \mathrm{~K}$, the thermal profile of the sample's surface was captured by an IR camera (DRS Tamarisk 320). In Figure 16c, the sample is a $20 \times 20 \times 4 \mathrm{~cm}^{3}$ mortar sample covered with a $13 \times 13 \mathrm{~cm}^{2}$ CFRP. There is a $2 \times 2 \mathrm{~cm}^{2}$ and $2 \mathrm{~mm}$ depth delamination in the center of the sample [58]. With $5 \mathrm{~s}$ heating time, measurements were performed at a $6 \mathrm{~cm}$ standoff distance. Meanwhile, measurements were also performed at a $45 \mathrm{~cm}$ standoff distance with $15 \mathrm{~s}$ heating time. Thermal profiles were captured before and after heating. In Figure 16d, the thermal image before heating is provided. Figure 16e shows the thermal image after $5 \mathrm{~s}$ heating. In their primary experiment results, the delamination in CFRP can be easily identified. Both the level of power and heating time should be optimized to detect small size disbands. In addition, they found that the measured result is evidently affected by edge effects with $45 \mathrm{~cm}$ standoff distance, as shown in Figure $16 \mathrm{f}$. 


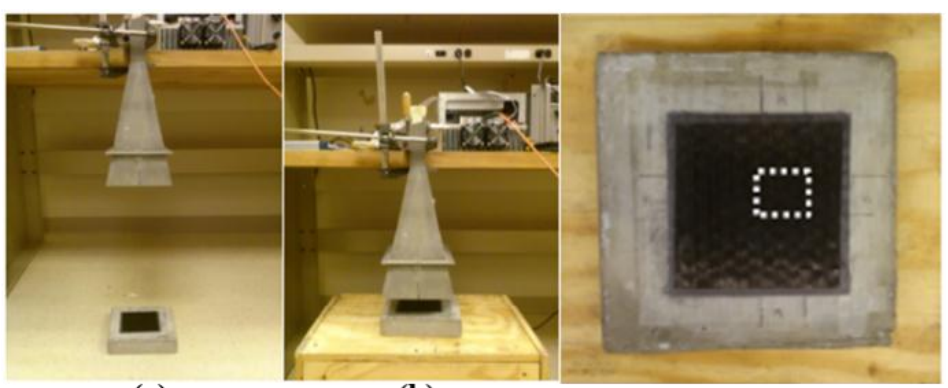

(a)

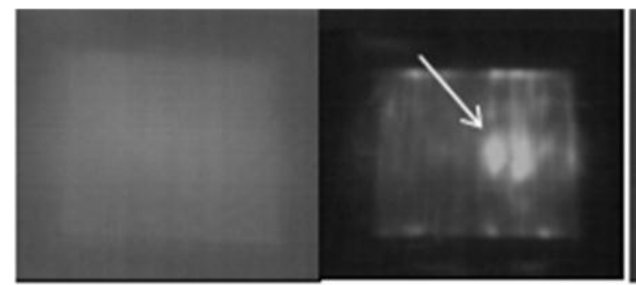

(d) (e) (c)

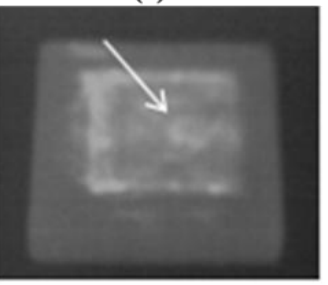

(f)

Figure 16. MWT measurement system setup used for $45 \mathrm{~cm}$ (a) and $6 \mathrm{~cm}$ (b) standoff, photograph of mortar sample with delamination (c). Measurements on mortar sample before heating (d), $6 \mathrm{~cm}$ standoff after $5 \mathrm{~s}$ heat (e) and $45 \mathrm{~cm}$ standoff after $15 \mathrm{~s}$ heat (f) [58]. Reprinted/reproduced with permission from IEEE.

Recently, Foudazi has shown that the MWT method can be used for detection of delaminations, debonding and cracks in rehabilitated cement-based materials [70]. The experimental setup is shown in Figure 17a. Three CFRP-strengthened cement-based specimens have been measured (a unbonded defect was made by placing a $5 \mathrm{~mm}$ thin sheet of foam with dimensions of $6 \mathrm{~cm} \times 8 \mathrm{~cm}$ in a sample with $52 \times 38 \times 9 \mathrm{~cm}^{3}$, several delaminations (with thicknesses ranging from $1 \mathrm{~mm}$ to $3 \mathrm{~mm}$ and areas ranging from $10 \mathrm{~cm}^{2}$ to $100 \mathrm{~cm}^{2}$ ) have been formed in a sample with dimensions of $52 \times 38 \times 7.8 \mathrm{~cm}^{3}$, the crack sample had dimensions of $52 \times 38 \times 9 \mathrm{~cm}^{3}$ ), as shown in Figure 17b. Thermal profiles for these specimens are illustrated in Figure 17c. The approximate location and the size information about defects in these specimens have been obtained. Meanwhile, the temperature of the defect will be affected by the orientation of the carbon fibers (due to the electric field difference). In their initial experimental results, for the case of unidirectional carbon fiber, if the electric field is along the fiber direction, the temperature change for the defected area will be smaller compared to the case of perpendicular polarization. This is due to the different electromagnetic response of the carbon fiber at different polarizations. In other words, if the wave is parallel to the fiber orientation, it will react as an electric conductor, while for the perpendicular case it is similar to high loss dielectric materials. Additionally, the thermal contrast (TC) between healthy and defective areas is much greater. Moreover, increasing defect dimensions also led to a greater TC.

Furthermore, the authors used MWT to monitor debonding in CFRP by using different excitation antennas [64]. A horn antenna linked with a double-ridged waveguide operating at frequency ranged from $0.75 \mathrm{GHz}$ to $18 \mathrm{GHz}$ was employed. The aperture size of this antenna is $14 \times 24 \mathrm{~cm}^{2}$. In Figure 18a, the CFRP sample is $30 \times 30 \times 0.2 \mathrm{~cm}^{3}$ backed with $40 \times 40 \times 5 \mathrm{~cm}^{3}$ Al sheet which containing six debonds with dimensions of $6 \times 6 \mathrm{~cm}^{2}, 5 \times 5 \mathrm{~cm}^{2}, 4 \times 4 \mathrm{~cm}^{2}, 3 \times 3 \mathrm{~cm}^{2}, 2 \times 2 \mathrm{~cm}^{2}$, and $1 \times 1 \mathrm{~cm}^{2}$, respectively. Figure $18 \mathrm{~b}$ shows top and side views of the CFRP backed by a layer of Al sheet. During experiment, the sample under test was illuminated at $2.4 \mathrm{GHz}$ microwave signal of different power $(50,100,150$ and $200 \mathrm{~W})$. In addition, the effect of the heating time (from $10 \mathrm{~s}$ to $30 \mathrm{~s}$ ) has been investigated by using CST Microwave Studio and MultiPhysics Studio. As shown in Figure 18c,d, normalized thermal images of CFRP with different excitation power levels at $10 \mathrm{~s}$ and $30 \mathrm{~s}$ have been demonstrated. In the preliminary experimental results, they found that a higher excitation microwave power is needed for a smaller debond detection. In addition, the debonding becomes clearly visible 
with increasing excitation power due to the temperature difference increase. Therefore, increasing the incident power improves the detection of small disbonds. Meanwhile, an increase of the heating time leads to an increased temperature throughout the sample under test, thereby the possibility of detecting the disbonds is reduced, therefore, the heating time must be optimized according to the actual situation.

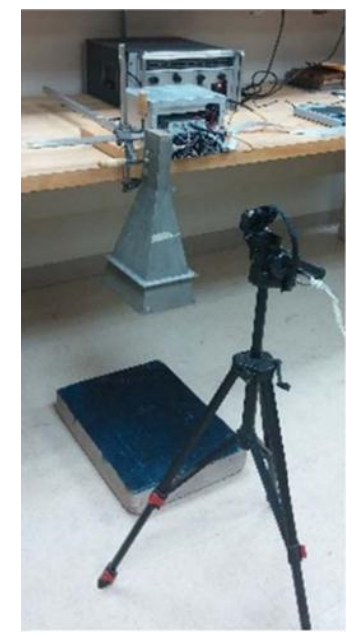

(a)
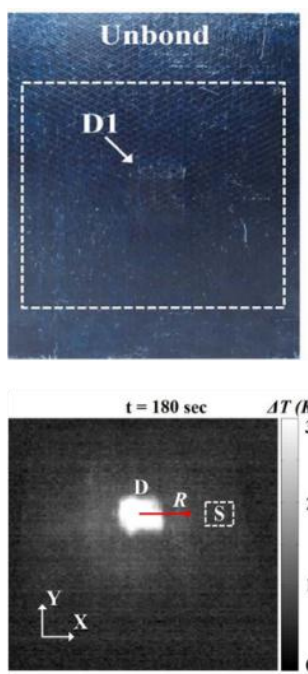

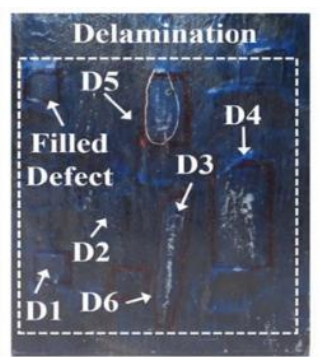

(b)

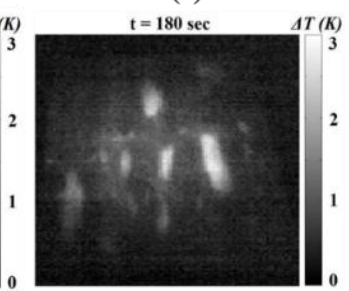

(c)
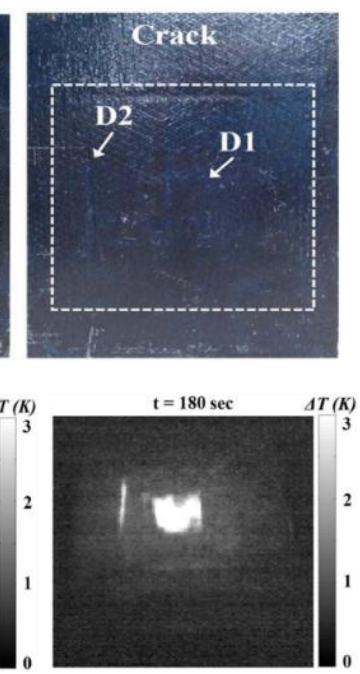

Figure 17. MWT measurement setup (a), samples under test (b) and thermal profiles for samples under test (c) [70]. Reprinted/reproduced with permission from IEEE.

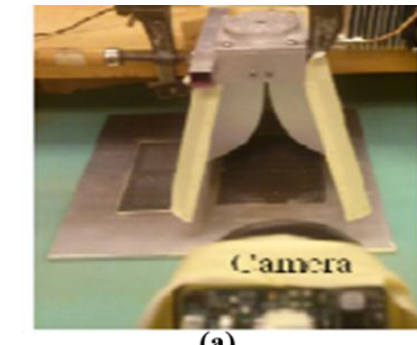

(a)

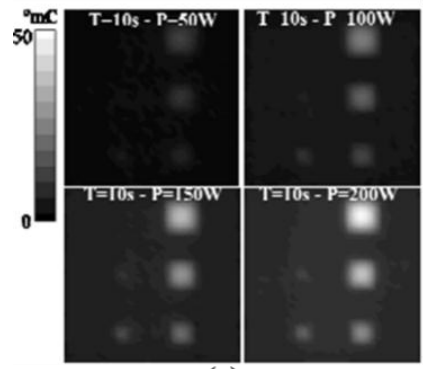

(c)

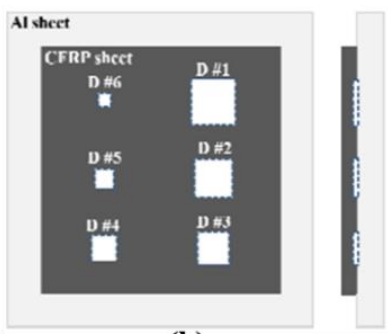

(b)

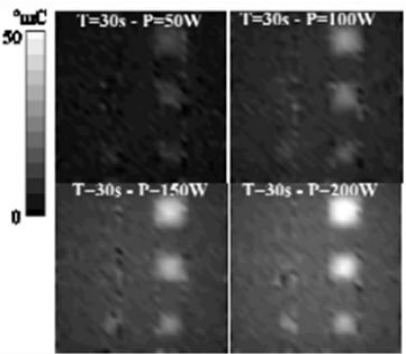

(d)

Figure 18. MWT experimental setup (a), sample (b), measurement results for $10 \mathrm{~s}$ heating (c) and $30 \mathrm{~s}$ heating (d) [64]. Reprinted/reproduced with permission from IEEE.

A microwave time-resolved infrared radiometry system was proposed by scientists in The John Hopkins University [71]. The experimental setup is shown in Figure 19a. $9 \mathrm{GHz}$ microwave signals were produced by an HP 6890B Oscillator. A Hughes 1277 X-band traveling wave tube amplifier was used to amplify these signals and then to feed them into a rectangular waveguide linked with a single flare horn antenna. The beam width of this horn antenna is about $50^{\circ}$ and the sample was placed about $15 \mathrm{~cm}$ away. $2.3 \mathrm{~W}$ input power was transmitted to the antenna and a $20 \mathrm{~mW} / \mathrm{cm}^{2}$ power 
density was created for the experimental study. Both the polarization of the microwave and the angle of incidence were controlled. By operating in the $3 \mu \mathrm{m}-5 \mu \mathrm{m}$ band, a $128 \times 128 \mathrm{InSb}$ focal plane array infrared camera was used to monitor the surface temperature of the sample under test. Before, during and after the application of the microwave step heating pulse, a series of frames were recorded for time-dependent measurements. In the initial experimental results, the authors measured carbon fibers with two different depths $(0.25 \mathrm{~mm}$ and $0.75 \mathrm{~mm})$ in fiberglass-epoxy. The temperature at the center of the fiber is shown in Figure 19b. Moreover, they found that the experimental data can be fitted with a solid line. The determination of surface layer thickness and thermal diffusivity can be almost independent from the surface properties of the layer.

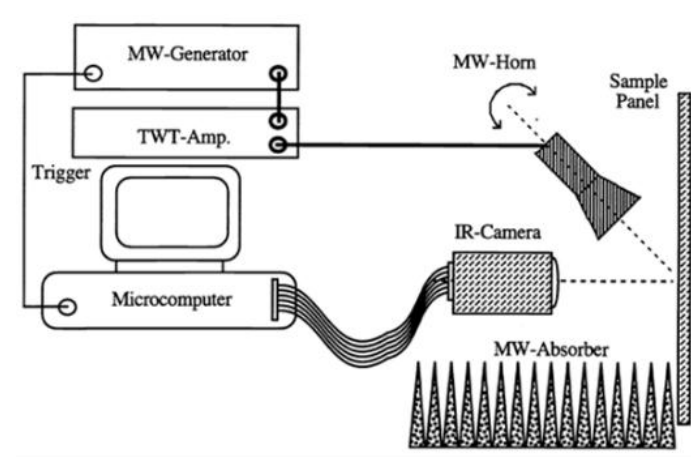

(a)

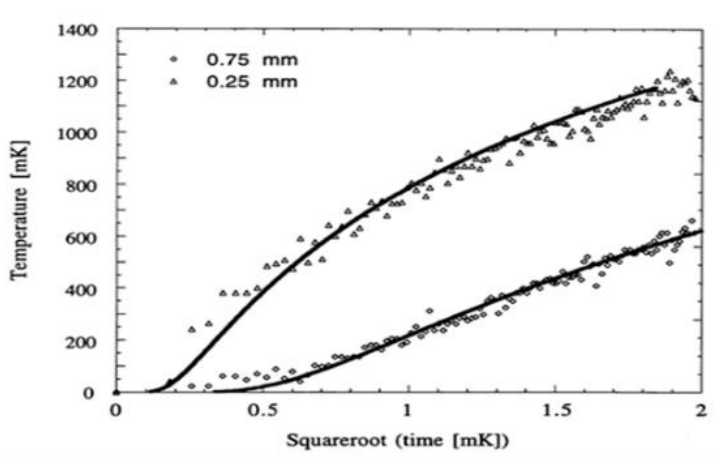

(b)

Figure 19. Schematic diagram of the experimental setup in The John Hopkins University (a) and Surface temperature as a function of square root time for a single point on fibers in $0.25 \mathrm{~mm}$ and $0.75 \mathrm{~mm}$ depth (b) [71]. Reprinted/reproduced with permission from SPIE.

Lee et al. proposed a microwave probe pumping technique to characterize the anisotropic electrical conductivity in carbon-fiber composite materials [69]. They used CST Microwave Studio to investigate the electromagnetic field distribution with different anisotropic conductivity. Two $10 \mathrm{~mm}$ coaxial probes were used to pump and scan the microwave field. The pumping probe was fixed on the backside of the sample under test. The near-field distribution was scanned by the scanning probe. A spectrometer was used to measure the microwave power. A network analyzer was used as the microwave source with a continuous mode. A FLIR T620 was used for measurement. A $1 \mathrm{GHz}$ microwave source with $20 \mathrm{dbm}$ power was used during the measurements. A $50 \times 50 \times 0.1 \mathrm{~mm}^{3}$ carbon-fiber/PEEK composite sheet with a defect (characteristic length is $5 \mathrm{~mm}$ ) has been measured. In the initial experimental results, they obtained an intense area around the scanning probe. Moreover, they found that the conductivity of the carbon-fiber/PEEK has an elliptical distribution.

\subsection{Honeycomb Structures}

Microwave pulsed thermography for water measurement in honeycomb materials was developed by scientists in Poland [72]. They introduced $2 \mathrm{GHz}$ antennas with a $30^{\circ}$ beam width. The surface of a honeycomb sample was illuminated with a $30 \mathrm{~mW} / \mathrm{cm}^{2}$ power density. The antenna and IR camera were arranged in a reflection configuration. The proposed MWT detection system is shown in Figure 20a. The antenna was located at $1 \mathrm{~m}$ away from the sample under test and the IR camera was placed at $0.7 \mathrm{~m}$. The sample was a $290 \times 215 \mathrm{~mm}^{2}$ sandwich panel with two $0.7 \mathrm{~mm}$ thickness Fibredux face skins. Different quantities of water (5.0, 2.5, 1.2 and $<1 \mathrm{~mL}$ ) are introduced in the sample to form four defects. Microwaves were used to irradiate the sample for $5 \mathrm{~s}$, and then the IR camera was used to capture thermal images for $20 \mathrm{~s}$ at a rate of $1 \mathrm{~Hz}$. In their experiment results, as shown in Figure 20b, the location of water can be well visible even in small quantities with the reflection and transmission arrangement, but it is difficult to qualify precisely the water content due to the phenomenon of longitudinal heat diffusion. 


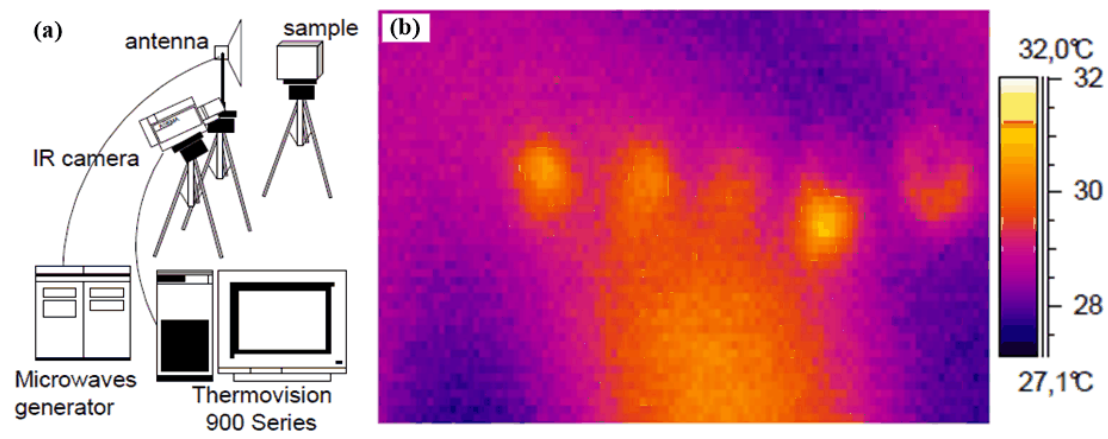

Figure 20. MWT setup at the Military Institute of Armament Technology (a) and results for water in the honeycomb material (b) [72].

\subsection{Cement Based Composite}

Foudazi et al. proposed active MWT to evaluate steel fiber distribution in cement-based mortars [73]. $200 \times 200 \times 200 \mathrm{~mm}^{3}$ fiber-reinforced cement-based mortar (FRCM) samples were measured. The steel fibers have diameters of $0.55 \mathrm{~mm}$ and lengths of $30 \mathrm{~mm}$. The effects of clumping, dielectric properties and fiber depth have been evaluated with a full-wave coupled electromagnetic-thermal simulation which was conducted by using CST MultiPhysics Studio ${ }^{\mathrm{TM}}$. As illustrated in Figure 21a, microwave signals were generated by a signal generator at the desired $2.4 \mathrm{GHz}$ operational frequency. A $50 \mathrm{~W}$ power amplifier was used to amplify the excitation power level. A horn antenna was used to radiate a relatively uniform microwave excitation toward the sample's surface. A DRS Tamarisk 320 thermal camera was utilized to capture the surface thermal profile of the sample.

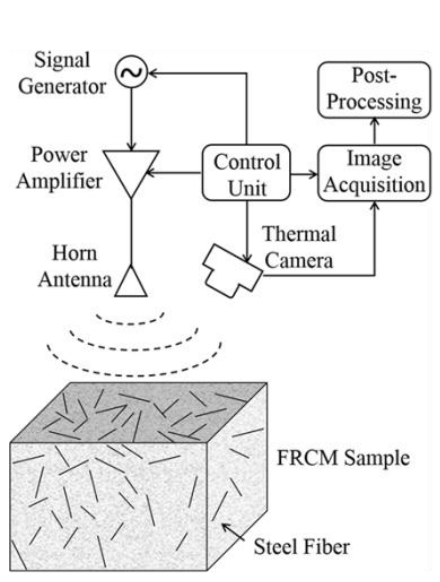

(a)

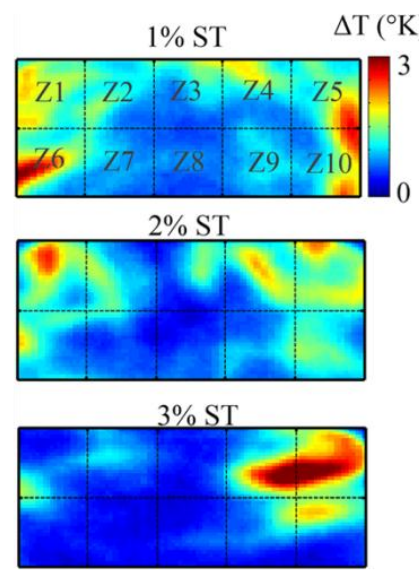

(b)

Figure 21. MWT measurement setup (a) and specimen surface temperature variation with different steel fiber contents (b) [73]. Reprinted/reproduced with permission from Springer.

During measurements, microwave energy was applied for $30 \mathrm{~s}$ and an additional $90 \mathrm{~s}$ of thermal profile measurement followed to capture the cooling period. As shown in Figure 21b, surface temperature differences after $30 \mathrm{~s}$ microwave heating were provided for $1 \%, 2 \%$ and $3 \%$ of steel fiber contents. In their primary experiment results, they found that a larger temperature difference was contributed by the induced surface current on areas containing steel fibers. Therefore, with increasing volume content of steel fibers, the temperature will increase. Due to variation in heating associated with induced surface current and dielectric heating, fiber depth and dielectric properties of mortar have a significant influence on the temperature difference at the surface of samples. They found that 
MWT is capable of determining the presence of the fiber clumping in the cement-based composite structures: $1 \%$ and $2 \%$ steel fibers are shown to have higher surface temperature difference compared to the sample made with $3 \%$ fiber content.

\subsection{Advanced Signal and Image Processing Methods}

Microwave lock-in thermography has been developed by scientists at Politecnico di Bari [74]. A function generator was used to control the power by switching the oven off/on. The frequency of excitation was $0.1 \mathrm{~Hz}$. As shown in Figure 22a, the IR camera was positioned at $15 \mathrm{~cm}$ from the oven to allow it to focus on and frame the whole specimen. The dimensions of the specimen were $76 \mathrm{~mm}$ in length, $76 \mathrm{~mm}$ in width and $8 \mathrm{~mm}$ in thickness. Due to the low heat diffusion velocity and thermal conductivity, a strong drift in the temperature evolution over time is noted. Moreover, this setup can avoid damage due to possible microwave leakage. To obtain the amplitude and the phase information, Fast Fourier Transform-based algorithms were used to process the thermal image data which acquires thermal images frame by frame over time. Figure $22 b$ shows the phase image and Figure 22c shows amplitude image. In the experimental results, the problem of the specimen's edges was observed. Due to the interaction between the specimen geometry and the electromagnetic field, a high temperature was exhibited near the edge of the specimen. Nevertheless, the authors could clearly identify the damage area in the captured thermograms. In addition, quantitative analysis of the damaged areas showed a good agreement between the defect area results obtained with microwave thermography $\left(1693 \mathrm{~mm}^{2}\right)$ and X-ray scanning $\left(1385 \mathrm{~mm}^{2}\right)$.

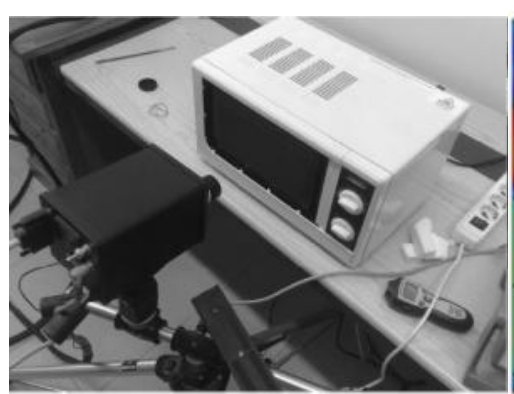

(a)

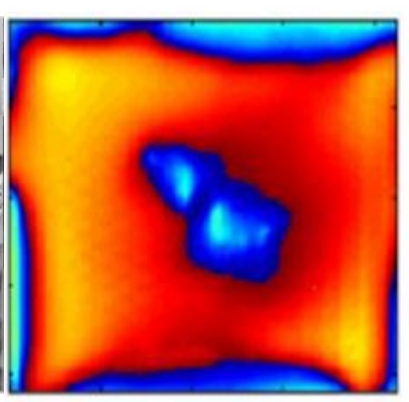

(b)

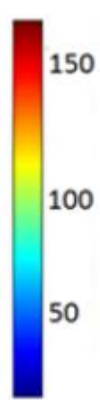

(1)

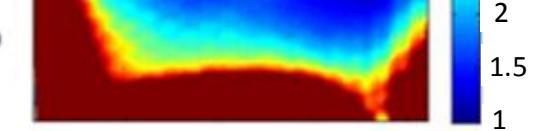

(c)

Figure 22. The experimental set-up used for relay (a), lock-in phase image (b) and amplitude image (c) [74].

In 2014, Palumbo et al. investigated MWT for quantitative evaluation of damaged areas in CFRP through experiments and numerical simulations [75]. Damaged CFRP samples were inspected by microwave pulsed thermography. The dimensions of the four sandwich tested specimens were $76 \times 76 \mathrm{~mm}^{2}$ with $8 \mathrm{~mm}$ thickness. Non-linear heating behavior was characterized and the undamaged area exhibited a higher slope during the heating and cooling phases. A new approach was proposed to process the obtained thermographic data. Numerical simulations were carried out to assess the sensitivity. An IR camera was located at $150 \mathrm{~mm}$ from the samples under test. To acquire the heating phase and subsequent cooling phase, the IR camera recorded for $7 \mathrm{~s}$ at $100 \mathrm{~Hz}$. This proposed technique offers advantages in term of testing time (only $2 \mathrm{~s}$ of heating and a very fast data processing). In Figure 23a, X-ray images of the specimens under test are provided for comparison with the MWT results. As shown in Figure $23 \mathrm{~b}, \mathrm{~T}_{\max }$ analysis can be used to quantitatively indicate damaged areas located at a greater depth. The authors proposed a new algorithm based on the non-linear heating and cooling thermal behavior of damaged and undamaged areas for the quantification of damaged areas. The image after the data binarization is shown in Figure 23c. The location and size information of the damaged area can be obtained from these measured results. Quantitative analysis of the damaged areas shows a good agreement between results obtained with microwave thermography $\left(784.3 \mathrm{~mm}^{2}\right.$ with 
heating slope), X-ray $\left(769.4 \mathrm{~mm}^{2}\right)$ and lock-in thermography $\left(779.3 \mathrm{~mm}^{2}\right)$. The size of the minimum resolvable defect was $2 \times 2 \times 0.5 \mathrm{~mm}^{3}$, with a depth of $1.3 \mathrm{~mm}$.
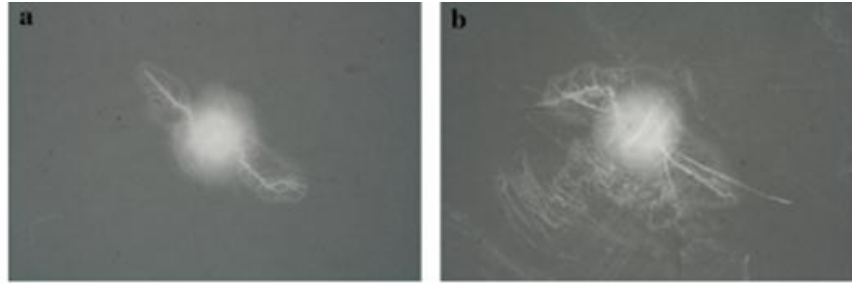

(a)
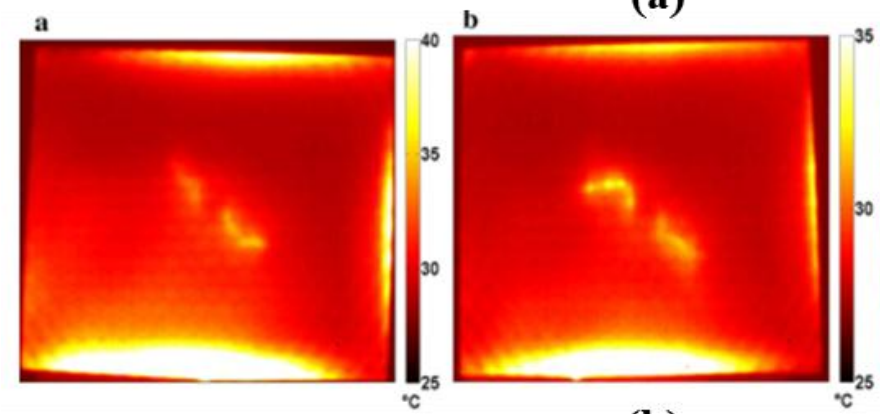

(b)
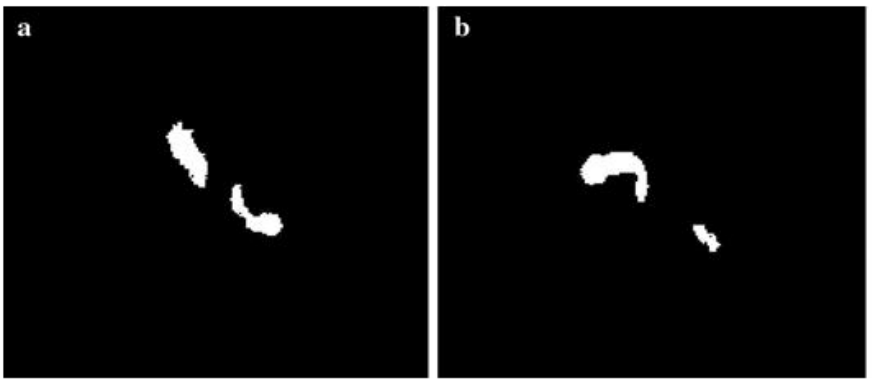

(c)
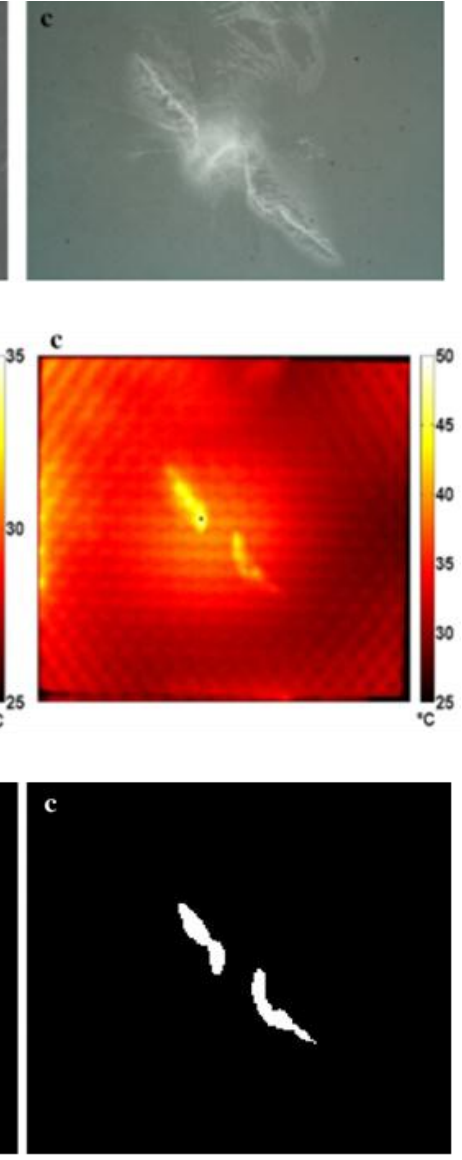

Figure 23. X-ray images of three samples (a), $\mathrm{T}_{\max }$ maps during all acquisition sequence (b), and binary images obtained by $\mathrm{T}_{\max }$ maps (c) [75]. Reprinted/reproduced with permission from Springer.

Usamentiaga et al. proposed an artificial neural network for automatic energy estimation of impact damages in carbon fiber composite materials, but the data acquisition time required for each inspection area was at least $30 \mathrm{~s}$ [76]. Three specimens were measured: specimen 1 was a carbon fiber composite made up of 12 plies with $2.5 \mathrm{~mm}$ in thickness. Specimens 2 and 3 were composite panels with two stiff facings made of carbon fiber and a low density material bonded between them. These two specimens have two valid sides, side A made up of six plies (1.5 $\mathrm{mm}$ in thickness) and side B made up of 12 plies ( $2.5 \mathrm{~mm}$ in thickness). A FLIR SC5000 IR camera was used to acquire infrared images for damages caused by impacts of different energy, ranging from $6 \mathrm{~J}$ to $50 \mathrm{~J}$. With 12 bits per pixel, $320 \times 256$ pixel thermal images are produced by the FLIR SC5000 and its' thermal sensitivity is $0.02 \mathrm{~K}$. To cut down the number of obtained images, the experimental acquisition rate is $50 \mathrm{~Hz}$ while the maximum frame rate is $383 \mathrm{~Hz}$. To improve the signal-to-noise ratio in the thermal images, a post-processing method was applied. With a Discrete Fourier Transform (DFT), the temperature-time history of each pixel during the heating period is transformed into the frequency domain and the phase information can be calculated based on it. As shown in Figure 24, the value below each defect is the estimated impact energy and the real impact energy is the number in brackets. In their primary experiment results, the impact energy of nearly half of the defects was estimated with an error of less than $2.5 \mathrm{~J}$. This percentage increases to $80 \%$ when the considered error is $5 \mathrm{~J}$, and nearly $100 \%$ 
when the estimated error is $10 \mathrm{~J}$. The results indicate that an artificial neural network (ANN) is able to quantitatively characterize impact damages.

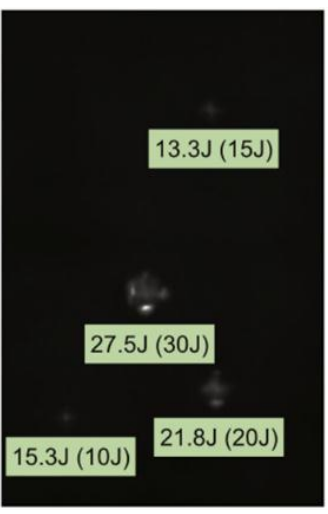

(a)

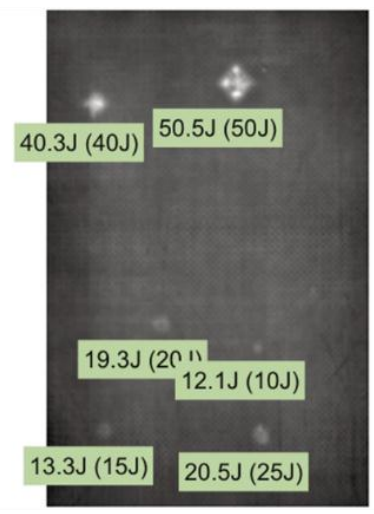

(b)

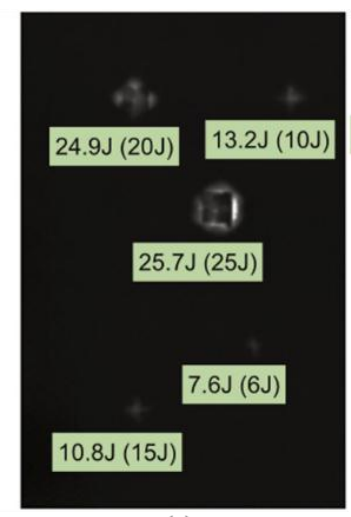

(c)

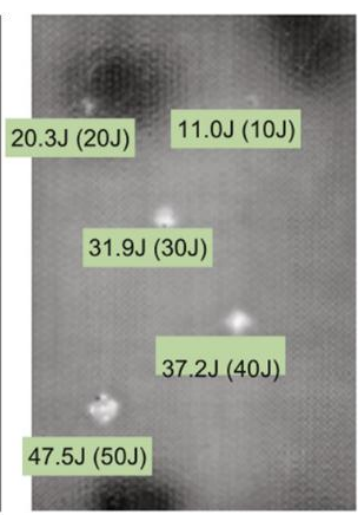

(d)

Figure 24. Estimated impact energy using artificial neural networks: specimen 2 front side (a), specimen 2 backside (b), specimen 3 front side (c), specimen 3 backside (d) [76]. Reprinted/reproduced with permission from Elsevier.

In summary, the purpose of adopting advanced signal processing methods in MWT is to eliminate noise, increase the signal to noise ratio for extracting the abnormality information of defects, enhance the contrast of detection images and improve the assessment accuracy. Meanwhile, the inspection time can be further reduced.

\section{Discussion}

\subsection{Comparison with Other Excitation Sources}

As mentioned before, a thermal contrast between surface/subsurface defects and the surrounding material can be produced by many energy sources. Some works are focused on the comparison between heating methods. For example, Keo et al. [56] compared microwave infrared thermography with $\mathrm{CO}_{2}$ laser thermography. MWT was found to be more suitable for the detection of deeper defects while $\mathrm{CO}_{2}$ laser thermography was more suitable for the detection of surface/near surface defects in CFRP.

According to a literature review [14,30,56,77], a comparison between MWT and other thermography excitation sources has been provided in Table 3. Due to the use of an IR camera, most of the thermography methods can offer fast inspection, non-contact, full-field, great sensitivity, high resolution, and quantitative analyses. As listed in Table 3, energy sources can be divided into:

1. Flash/lamp: halogen or IR lamps are commonly employed for a long period in large inspection areas with an $x-y$ scanner/robot. In all cases, the measurement surface is been illumined by light to transfer heat and to propagate inside the specimen (containing a wavelength range from the ultraviolet, visible and infrared spectrum).

2. Laser: the heat is introduced into the material under test by the laser. Compared with lamps, a scan of the inspection area is needed.

3. Mechanical: sound or ultrasound waves are injected by transducers. With waves propagating through the specimen, heat is produced by slapping and rubbing of the surfaces (mostly in the defect areas). Compared with optical excitation, non-uniform heating is considerably reduced and the visibility of sub-surface defects is improved.

4. Induction: eddy currents are generated by an excitation coil. The penetration depth varies inversely with the operation frequency. The induction heating is limited to conductive materials. 
Compared with mechanical heating, heating non-uniformities have less influence in induction heating since heat is produced locally.

5. Microwave: the heat is introduced into the specimen by a time-gated microwave excitation source. The sub-surface microwave absorbing features can be used for measurements (such as metal bars/fibers, water-filled areas). By analyzing the time of the thermal images, quantitative defect information can be extracted (such as depth and size).

Table 3. Comparison of thermography inspection methods with different excitation sources.

\begin{tabular}{cll}
\hline Heating Sources & \multicolumn{1}{c}{ Strengths } & \multicolumn{1}{c}{ Limitations } \\
\hline Flash, lamp & Non-contact, full-field, low cost, methods are mature & $\begin{array}{l}\text { Surface heating, impact of surface condition } \\
\text { on heating, heating reflection }\end{array}$ \\
\hline Laser & $\begin{array}{l}\text { Non-contact, remote heating from a far distance, } \\
\text { high sensitivity, great resolution, quantification, fast }\end{array}$ & $\begin{array}{l}\text { Heating area relies on excitation source, } \\
\text { scanning is required, more suitable for } \\
\text { surface defect detection }\end{array}$ \\
\hline Mechanical & $\begin{array}{l}\text { Full-field, high resolution, high sensitivity, } \\
\text { quantification, fast, selective heating }\end{array}$ & $\begin{array}{l}\text { Contact, know-how, specimen needs to be } \\
\text { fixed, lack of quantitative information }\end{array}$ \\
\hline Induction & $\begin{array}{l}\text { Non-contact, relatively low-cost of excitation system, } \\
\text { full-field, high resolution, great sensitivity, } \\
\text { quantification, fast, inner heating }\end{array}$ & $\begin{array}{l}\text { Limited to conductive material, } \\
\text { non-uniform heating, complex heating } \\
\text { system, near-field heating, heating area is } \\
\text { limited to the excitation coil }\end{array}$ \\
\hline \multirow{2}{*}{ Microwave } & $\begin{array}{l}\text { Non-contact, remote excitation, full-field, high } \\
\text { resolution, great sensitivity, quantification, fast, } \\
\text { uniform heating, selective heating }\end{array}$ & $\begin{array}{l}\text { Complex and expensive microwave } \\
\text { excitation system, electromagnetic radiation }\end{array}$ \\
\hline
\end{tabular}

\subsection{Comparison with Other NDT Methods}

Eight major categories of NDT techniques are listed in Table 4. A comparison of these technologies is provided and an overview of each method given to identify the advantages and limitations of current NDT techniques.

Table 4. Summary and comparison for MWT with major NDT methods.

\begin{tabular}{lll}
\hline NDT Techniques & Strength & Limitation \\
\hline $\begin{array}{l}\text { Ultrasound-echo/Phased } \\
\text { array/Linear array }\end{array}$ & $\begin{array}{l}\text { Great depth, high resolution, many } \\
\text { deployment options }\end{array}$ & $\begin{array}{l}\text { Sound attenuation, coupling for contact testing, } \\
\text { non-sensitive to surface defects }\end{array}$ \\
\hline Guide wave & Large areas & Sound attenuation, coupling for contact testing \\
\hline Acoustic emission & In-service, passive, large areas, & $\begin{array}{l}\text { Noise, bad quantitation, non-sensitive } \\
\text { to static defects }\end{array}$ \\
\hline Shearography & $\begin{array}{l}\text { Non-contact, low-cost, no surface treatment, full-field, fast, high sensitivity } \\
\text { Eddy current }\end{array}$ & $\begin{array}{l}\text { Sensitive to part movement, small } \\
\text { thickness/stiffness, require unique test set-ups, } \\
\text { expensive, hard to quantitatively analyze }\end{array}$ \\
\hline Microwave & $\begin{array}{l}\text { Non-contact, high resolution, suitable for } \\
\text { dielectric material }\end{array}$ & $\begin{array}{l}\text { Scanner required, near-field, lift-off influence } \\
\text { tofial, scanner required, sensitive }\end{array}$ \\
\hline Microwave thermography & $\begin{array}{l}\text { Non-contact, full-field, high resolution, } \\
\text { high sensitivity, quantification, fast, } \\
\text { uniform heating, selective heating }\end{array}$ & $\begin{array}{l}\text { Heating system complex, } \\
\text { electromagnetic radiation }\end{array}$ \\
\hline X-ray/Gamma-ray & $\begin{array}{l}\text { High resolution, non-contact } \\
\text { X-ray radiation hazards, operation complex, } \\
\text { scanner required }\end{array}$
\end{tabular}

For materials inspection, there is no universally applicable method. Selection of a particular NDT technique requires more consideration than the detection capabilities. Meanwhile, the application, portability of equipment, inspection schedule, inspection area, types of materials, accessibility, costs and expected defects types are also important. 


\subsection{Shortcomings of MWT}

From the MWT literature, it can be found that MWT is not always perfect for quantitative material detection. There are still many shortcomings in existing studies, which can be mainly summarized as follows:

1. Inadequate theoretical studies

Multi-physics coupling mechanisms of metal/composite materials detection with microwave thermography are not deeply studied. For example, composite materials are typically composed of a variety of materials, and the microwave heating principles of composite materials are different from those of conductive and dielectric materials. Meanwhile, the physical processes of MWT for material evaluation are very complex, which includes microwave heating, heat conduction, and heat diffusion. For example, microwave heating represents a dielectric loss in glass fiber composite materials, where it is a volumetric heating method; while microwave heating is Joule heat for conductive materials which is affected by skin effects, and it is a surface heating method.

2. Lack of study on excitation signal modulation and corresponding data processing methods

As mentioned above, IR thermography techniques can be subdivided into pulse thermography, lock-in thermography, pulse phase thermography and step heating thermography [14]. Many scholars have studied microwave pulse thermography, microwave step heating thermography and microwave lock-in thermography. However, no researcher has studied pulse phase microwave heating in the frequency domain. Microwave pulse phase thermography combines the advantages of MPT and MLT which can inhibit change in the surface emissivity and other negative factors; the pulse width can bring a stronger contrast and a deeper defect can be detected.

3. Lack of systematic research on microwave excitation module optimization

Microwave excitation module is an important part of MWT, and the heating effect is directly reliant on it. Furthermore, the subsequent thermal imaging is directly affected by rapid and uniform heating. British and Polish researchers have investigated waveguides as excitation modules [57,72]; French scholars have studied the pyramidal horn antenna as an excitation module [56]; South Korean scholars have studied the coaxial setup as excitation module [69]. However, the advantages and disadvantages of these microwave excitation modules are not thoroughly studied, which results in is it being difficult to achieve the optimal detection ability with MWT systems.

4. Lack of internal properties characterization and defect quantification methods

Temperature variation from the infrared camera is a result of joint action by the surface properties of materials (emissivity), internal thermal properties (thermal conductivity, diffusivity, interlayer reflection coefficient), electrical properties (conductivity and permittivity) and other factors. How to extract these features from the surface temperature response and to further quantitatively characterize the material properties is important and difficult in the current studies. Existing studies did not provide an effective method for property characterization and defect quantification.

5. Lack of automatic separation and damage area quantification methods

Some scholars have studied several prefabricated macroscopic defects in composite materials (lamination defects, cracks and debonding, etc.), and experimental empirical formulas have been established; but there is a lack of related research on automatic separation of different defects and damage area quantification. The data acquired with MWT is an image sequence or a three-dimensional matrix. Matrix analysis method is theoretically possible to achieve fast imaging, automatic separation and damage area quantification. However, existing studies employed advanced matrix decomposition methods for MWT data processing. 


\section{Trends}

1. Multiple physics and new physics

The physical properties of the specimens are different which results in the physics of MWT being different. For example, composites are multi-layered and their parameters are anisotropic as a result of fiber reinforcement. In addition, several composite materials are often included in a composite structure (such as a sandwich structure). Hence, the physics of metals differ from those of composites. Furthermore, the effects of the electromagnetic field, microwave propagation and other multiple-physical field also need to be investigated, such as thermal pattern interpretation [78] in thermal optical flow [79], and the spatial-, time-, frequency-, and sparse-pattern domains. Thus, multiple physics and new physics-based MWT methods are required for materials evaluation.

\section{Computer simulation and modeling}

Over the last several years, computer modeling and simulation (such as method of moments or MoM and finite element method or FEM) have been employed for understanding the physics during MWT measurements (such as microwave radiation and propagation, heat generation and diffusion). In the past, researchers have investigated three different approaches to resolving the electromagnetic phenomena of microwave propagation and heating processes. Firstly, time-domain solvers have been applied to microwave heating problems [80]. These use a time-marching algorithm to predict the electric and magnetic fields at the next time step. Secondly, frequency-domain methods have been investigated [81], where the numerical solution strategy uses a particular frequency to predict the electric and magnetic fields. Lastly, a method that combines an efficient time-domain solver with the power of a frequency-domain solver, has been used to predict the power distribution generated in a lossy medium during microwave heating [82]. Moreover, the operational frequency and radiation pattern of microwave excitation system can be optimized with simulation and modeling for better detection performance. In addition, the influence of materials' properties (such as conductivity, dielectric, size and shape) can be investigated with simulation and the total cost of experiments will be reduced. What's more, the parameters of defects (such as location, size, orientation and shape) can be examined. For composite materials, the influence of different fiber orientations in the microwave EM field can be investigated too. Therefore, simulation and modeling are needed to improve the reliability and accuracy of MWT systems.

\section{Microwave excitation system optimization}

MWT is based on microwave heating. The thermal profile of a material under test is created by an IR camera after microwave excitation. With MWT, a large amount of microwave excitation systems can be used to introduce the heat, however, the heating efficiency of microwave excitation systems is not only dependent on the properties of the microwave system (such as operational frequency, radiation pattern and power, etc.) but also relies on the physical properties of the material under test (such as size, shape, conductivity, dielectrics and microwave energy absorbing ability, etc.). Thus, the optimization of microwave excitation systems is required to improve the ability and sensitivity of MWT systems.

\section{Signal processing algorithms}

To extract useful features from the captured thermal images, advanced signal processing algorithms have been used. These algorithms includes wavelet transform [83], independent components analysis (ICA) [84], principal components analysis (PCA) [85,86], pattern recognition [87], support vector machine [88,89] and Tucker decomposition [90]. With suitable signal processing algorithms, the inspection results for size and depth identification, subsurface defect detection, emissivity variation reduction and defect dimension quantification can be significantly improved. 
Therefore, more advanced signal processing algorithms are needed to further improve the sensitivity and quantification ability of MWT systems.

5. Intelligent inspection systems

The efficiency of a MWT system can be improved by implementing an intelligent inspection system with artificial intelligence. As various types of defects can be acquired during material measurement, the treatment for different types of defects is different. Taking a composite material for example, the most common embedded defects are delamination, adhesive debonding and out-of-plane waviness. These defects are the most typical defects observed during manufacturing which need to be identified to improve the manufacturing quality of the composite. Therefore, it is important to classify the defect type with an intelligent inspection system. As computers become increasingly capable, artificial intelligence methods can be used in MWT to reduce the inspection time and improve the reliability of MWT systems. For example, Moomen et al. employed machine learning for feature selection in microwave NDT [91].

6. Mobile inspection systems

For a large material under test, the MWT needs to be placed in a mobile robot or a vehicle. In Figure 25, a MWT inspection system has been combined with a vehicle [61]. The inspection time of MWT for a large material can be significantly reduced. The whole inspection can be performed autonomously. The safety and efficiency of the MWT systems are being improved too. However, lightweight equipment and advanced detection algorithms including compressed sensing are also required in order to provide automatic inspection capability.

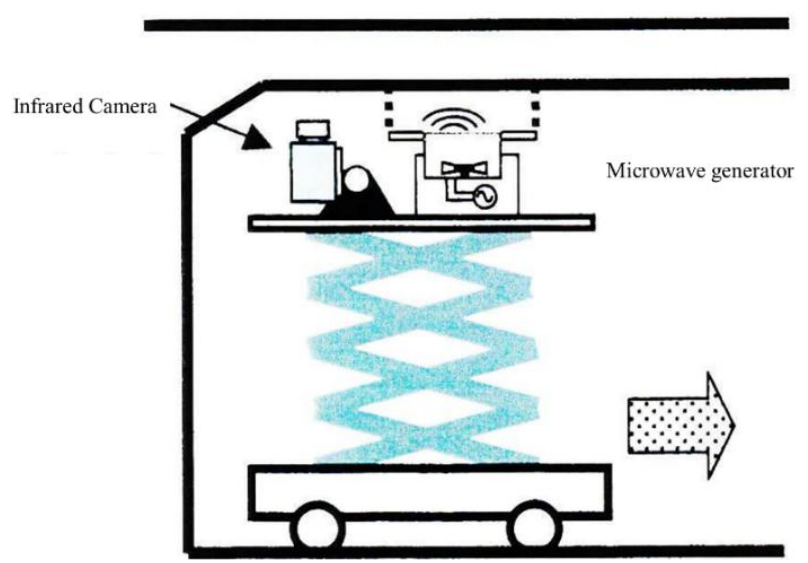

Figure 25. MWT combined with a vehicle [61]. Reprinted/reproduced with permission from SPIE.

\section{Conclusions}

The basic principles and types of MWT have been reviewed in this paper. MWT exhibits great potential, including fast heating, high resolution, fast inspection and high sensitivity, no contact requirement and better detectability for inner defects. Moreover, the manufacturing quality and reliability of materials can be improved to prevent failures. In this work, a comprehensive review of MWT techniques for material inspection has been reported based on a detailed literature survey. Firstly, the theory of MWT has been presented and MWT has been classified into four categories. Then, the development of MWT has been outlined through case studies. Next, limitations in current MWT research have been outlined based on detailed comparisons. Finally, some research trends in MWT are predicted. It is concluded that:

1. MWT combines the advantages of microwave technology and infrared thermography. A higher heating efficiency and uniform heating pattern can be expected. A full-field, non-contact, fast detection can be performed. 
2. MWT can be divided into MPT, MPPT, MST and MLT. In the near future, microwave frequency modulated thermography and microwave pulsed phase thermography will be achieved.

3. MWT is a fast and effective non-destructive method for material inspection, especially for water/defects identification in concrete/composite structures.

Acknowledgments: This work was supported by National Natural Science Foundation of China (61601125 and 61501483), National Key Research and Development Program of China (2016YFF0203400), Natural Science Foundation of Fujian Province (2016J05152) and Fujian Province Young and Middle Age Education Research Fund (JA15577).

Conflicts of Interest: The authors declare no conflict of interest.

$\begin{array}{ll}\text { Abbreviations } \\ \text { AHT } & \text { Abnormal heating thermography } \\ \text { ANN } & \text { Artificial neural networks } \\ \text { CFRP } & \text { Carbon fiber reinforced polymer } \\ \text { DFT } & \text { Discrete Fourier transform } \\ \text { ECLT } & \text { Eddy current lock-in thermography } \\ \text { ECPT } & \text { Eddy current pulsed thermography } \\ \text { ECPPT } & \text { Eddy current pulsed phase thermography } \\ \text { ECST } & \text { Eddy current step thermography } \\ \text { FEM } & \text { Finite element method } \\ \text { FRCM } & \text { Fiber-reinforced cement-based mortars } \\ \text { GFRP } & \text { Glass fiber reinforced polymer } \\ \text { LT } & \text { Lock-in thermography } \\ \text { MLT } & \text { Microwave lock-in thermography } \\ \text { MoM } & \text { Method of moments } \\ \text { MPT } & \text { Microwave pulsed thermography } \\ \text { MPPT } & \text { Microwave pulsed phase thermography } \\ \text { MST } & \text { Microwave step thermography } \\ \text { MT } & \text { Modulated thermography } \\ \text { MUT } & \text { Material under test } \\ \text { MWT } & \text { Microwave thermography } \\ \text { NDT } & \text { Nondestructive testing } \\ \text { PMC } & \text { Polymer matrix composites } \\ \text { PPT } & \text { Pulsed phase thermography } \\ \text { PT } & \text { Pulsed thermography } \\ \text { SHM } & \text { Structural health monitoring } \\ \text { SHT } & \text { Surface heating thermography } \\ \text { ST } & \text { Step thermography } \\ \text { VHT } & \text { Volume heating thermography } \\ & \end{array}$

\section{References}

1. Bakht, B.; Mufti, A. Bridges: Analysis, Design, Structural Health Monitoring, and Rehabilitation; Springer: Cham, Switzerland, 2015.

2. Hellier, C. Handbook of Nondestructive Evaluation; Mcgraw-hill: New York, NY, USA, 2001.

3. Maldague, X.P. Introduction to NDT by active infrared thermography. Mater. Eval. 2002, 60, 1060-1073.

4. Vergani, L.; Colombo, C.; Libonati, F. A review of thermographic techniques for damage investigation in composites. Fract. Struct. Integr. Ann. 2014, 8. [CrossRef]

5. Sun, J.G. Analysis of Pulsed Thermography Methods for Defect Depth Prediction. J. Heat Transf. 2005, 128, 329-338. [CrossRef]

6. Czichos, H. Handbook of Technical Diagnostics; Springer: Berlin, Germany, 2013; Volume 40, pp. 43-68.

7. Shalin, R.E.E. Polymer Matrix Composites; Springer Science \& Business Media: Berlin, Germany, 2012. 
8. Zalameda, J.N.; Burke, E.R.; Parker, F.R.; Seebo, J.P.; Wright, C.W.; Bly, J.B. Thermography inspection for early detection of composite damage in structures during fatigue loading. Proc. SPIE 2012, 8354. [CrossRef]

9. Waugh, R.C.; Dulieu-Barton, J.M.; Quinn, S. Modelling and evaluation of pulsed and pulse phase thermography through application of composite and metallic case studies. NDT E Int. 2014, 66, 52-66. [CrossRef]

10. Roche, J.M. Common tools for quantitative time-resolved pulse and step-heating thermography-Part I: Theoretical basis. Quant. Infrared Thermogr. J. 2014, 11, 43-56.

11. Maldague, X.P. Theory and Practice of Infrared Technology for Nondestructive Testing; John Wiley Interscience: New York, NY, USA, 2001.

12. Castanedo, C.I. Quantitative Subsurface Defect Evaluation by Pulsed Phase Thermography: Depth Retrieval with the Phase; Université Laval: Québec City, QC, Canada, 2005.

13. Maldague, X.P.; Marinetti, S. Pulsed phase infrared thermography. J. Appl. Phys. 1996, 79, $2694-2698$. [CrossRef]

14. Yang, R.; He, Y. Optically and Non-optically Excited Thermography for Composites: A review. Infrared Phys. Technol. 2016, 75, 26-50. [CrossRef]

15. Li, T.; Almond, D.P.; Rees, D.A.S. Crack imaging by scanning pulsed laser spot thermography. NDT E Int. 2011, 44, 216-225. [CrossRef]

16. Wilson, J.; Tian, G.Y.; Abidin, I.Z.; Yang, S.; Almond, D. Pulsed eddy current thermography: System development and evaluation. Insight Non-Destr. Test. Cond. Monit. 2010, 52, 87-90. [CrossRef]

17. Riegert, G.; Zweschper, T.; Busse, G. Eddy-current lockin-thermography: Method and its potential. J. Phys. IV Fr. 2005, 125, 587-591. [CrossRef]

18. He, Y.; Tian, G.; Pan, M.; Chen, D. Eddy current pulsed phase thermography and feature extraction. Appl. Phys. Lett. 2013, 103, 084104. [CrossRef]

19. Yang, R.; He, Y.; Gao, B.; Tian, G.Y.; Peng, J. Lateral heat conduction based eddy current thermography for detection of parallel cracks and rail tread oblique cracks. Measurement 2015, 66, 54-61. [CrossRef]

20. He, Y.; Pan, M.; Tian, G.Y.; Chen, D.; Tang, Y.; Zhang, H. Eddy current pulsed phase thermography for subsurface defect quantitatively evaluation. Appl. Phys. Lett. 2013, 103, 144108. [CrossRef]

21. He, Y.; Pan, M.; Chen, D.; Tian, G.Y.; Zhang, H. Eddy current step heating thermography for quantitatively evaluation. Appl. Phys. Lett. 2013, 103, 194101. [CrossRef]

22. He, Y.; Tian, G.; Pan, M.; Chen, D. Impact evaluation in carbon fiber reinforced plastic (CFRP) laminates using eddy current pulsed thermography. Compos. Struct. 2014, 109, 1-7. [CrossRef]

23. Zhang, H.; Gao, B.; Tian, G.Y.; Woo, W.L.; Bai, L. Metal defects sizing and detection under thick coating using microwave NDT. NDT E Int. 2013, 60, 52-61. [CrossRef]

24. Qaddoumi, N.N.; Saleh, W.M.; Abou-Khousa, M. Innovative Near-Field Microwave Nondestructive Testing of Corroded Metallic Structures Utilizing Open-Ended Rectangular Waveguide Probes. IEEE Trans. Instrum. Meas. 2007, 56, 1961-1966. [CrossRef]

25. Meredith, R. Engineers' Handbook of Industrial Microwave Heating; The Institution of Electrical Engineers: London, UK, 1998.

26. Wyckhuyse, A.; Maldague, X. A Study of Wood Inspection by Infrared Thermography, Part II: Thermography for Wood Defects Detection. Res. Nondestruct. Eval. 2001, 13, 13-22. [CrossRef]

27. Balageas, D.; Lemistre, M.; Levesque, P. Mine detection using the $\mathrm{EMIR}^{\circledR}$ method-Improved configuration using a mobile detection system. In Proceedings of the 7th International Conference on Quantitative Infrared Thermography (QIRT), Bordeaux, France, 7-11 July 2004.

28. Swiderski, W.; Hłosta, P.; Szugajew, L.; Usowicz, J. Microwave enhancement on thermal detection of buried objects. In Proceedings of the 11th International Conference on Quantitative InfraRed Thermography, Naples, Italy, 11-14 June 2012.

29. Vinson, J.R. Adhesive bonding of polymer composites. Polym. Eng. Sci. 1989, 29, 1325-1331. [CrossRef]

30. Yang, R.; He, Y.; Zhang, H. Progress and Trends in Nondestructive Testing and Evaluation for Wind Turbine Composite Blade. Renew. Sustain. Energy Rev. 2016, 60, 1225-1250. [CrossRef]

31. Ibarra-Castanedo, C.; Maldague, X. Review of pulse phase thermography. Proc. SPIE 2015, 9485. [CrossRef]

32. Kylili, A.; Fokaides, P.A.; Christou, P.; Kalogirou, S.A. Infrared thermography (IRT) applications for building diagnostics: A review. Appl. Energy 2014, 134, 531-549. [CrossRef] 
33. Bagavathiappan, S.; Lahiri, B.B.; Saravanan, T.; Philip, J.; Jayakumar, T. Infrared thermography for condition monitoring-A review. Infrared Phys. Technol. 2013, 60, 35-55. [CrossRef]

34. Yang, B.; Zhang, L.; Zhang, W.; Ai, Y. Non-destructive testing of wind turbine blades using an infrared thermography: A review. In Proceedings of the International Conference on Materials for Renewable Energy and Environment, Chengdu, China, 19-21 August 2013; pp. 407-410.

35. Ibarra-Castanedo, C.; Maldague, X. Pulsed phase thermography reviewed. Quant. Infrared Thermogr. J. 2004, 1, 47-70. [CrossRef]

36. Hung, Y.; Chen, Y.S.; Ng, S.; Liu, L.; Huang, Y.; Luk, B.; Ip, R.; Wu, C.; Chung, P. Review and comparison of shearography and active thermography for nondestructive evaluation. Mater. Sci. Eng. R Rep. 2009, 64, 73-112. [CrossRef]

37. Omar, M.A.; Zhou, Y. A quantitative review of three flash thermography processing routines. Infrared Phys. Technol. 2008, 51, 300-306. [CrossRef]

38. Ghosh, K.K.; Karbhari, V.M. A critical review of infrared thermography as a method for non-destructive evaluation of FRP rehabilitated structures. Int. J. Mater. Prod. Technol. 2006, 25, 241-266. [CrossRef]

39. Vavilov, V.P.; Burleigh, D.D. Review of pulsed thermal NDT: Physical principles, theory and data processing. NDT E Int. 2015, 73, 28-52. [CrossRef]

40. Banerjee, D.; Chattopadhyay, S.; Tuli, S. Infrared thermography in material research-A review of textile applications. Indian J. Fiber Text. Res. 2013, 38, 427-437.

41. Usamentiaga, R.; Venegas, P.; Guerediaga, J.; Vega, L.; Molleda, J.; Bulnes, F.G. Infrared thermography for temperature measurement and non-destructive testing. Sensors 2014, 14, 12305-12348. [CrossRef] [PubMed]

42. Meola, C.; Carlomagno, G.M. Application of infrared thermography to adhesion science. J. Adhes. Sci. Technol. 2006, 20, 589-632. [CrossRef]

43. Meola, C.; Carlomagno, G.M. Recent advances in the use of infrared thermography. Meas. Sci. Technol. 2004, 15, R27. [CrossRef]

44. Yang, R.; Zhang, H.; Li, T.; He, Y. An investigation and review into microwave thermography for NDT and SHM. In Proceedings of the IEEE Far East NDT New Technology \& Application Forum, Zhuhai, China, 28-31 May 2015; pp. 133-137.

45. He, Y.; Yang, R.; Zhang, H.; Zhou, D.; Wang, G. Volume or inside heating thermography using electromagnetic excitation for advanced composite materials. Int. J. Thermal Sci. 2017, 111, 41-49. [CrossRef]

46. Meredith, R. Engineers' Handbook of Industrial Microwave Heating [Book Review]. Power Eng. 1999, 13, 3.

47. Vrana, J.; Goldammer, M.; Bailey, K.; Rothenfusser, M.; Arnold, W. Induction and Conduction Thermography: Optimizing the Electromagnetic Excitation towards Application. AIP Conf. Proc. 2009, 1096, 518-525.

48. Shao, K.; Lavers, J.D. A skin depth-independent finite element method for Eddy current problems. IEEE Trans. Magn. 1986, 22, 1248-1250. [CrossRef]

49. Niliot, C.L.; Gallet, P. Infrared thermography applied to the resolution of inverse heat conduction problems: Recovery of heat line sources and boundary conditions. Revue Générale Thermique 1998, 37, 629-643. [CrossRef]

50. Salazar, A. Energy propagation of thermal waves. Eur. J. Phys. 2006, 27, 1349. [CrossRef]

51. Liu, J.; Yang, W.; Dai, J. Research on thermal wave processing of lock-in thermography based on analyzing image sequences for NDT. Infrared Phys. Technol. 2010, 53, 348-357. [CrossRef]

52. Osiander, R.; Spicer, J.W. Time-resolved infrared radiometry with step heating. A review. Revue Générale Thermique 1998, 37, 680-692. [CrossRef]

53. Yang, R.; He, Y.; Gao, B.; Tian, G.Y. Inductive pulsed phase thermography for reducing or enlarging the effect of surface emissivity variation. Appl. Phys. Lett. 2014, 105, 184103. [CrossRef]

54. Yang, R.; He, Y. Eddy current pulsed phase thermography considering volumetric induction heating for delamination evaluation in carbon fiber reinforced polymers. Appl. Phys. Lett. 2015, 106, 234103. [CrossRef]

55. He, Y.; Yang, R. Eddy Current Volume Heating Thermography and Phase Analysis for Imaging Characterization of Interface Delamination in CFRP. IEEE Trans. Ind. Inf. 2015, 11, 1287-1297. [CrossRef]

56. Keo, S.-A.; Defer, D.; Breaban, F.; Brachelet, F. Comparison between Microwave Infrared Thermography and $\mathrm{CO}_{2}$ Laser Infrared Thermography in Defect Detection in Applications with CFRP. Mater. Sci. Appl. 2013, 4, 600-605. 
57. Cheng, L.; Tian, G.Y.; Szymanik, B. Feasibility studies on microwave heating for nondestructive evaluation of glass fibre reinforced plastic composites. In Proceedings of the IEEE International Instrumentation and Measurement Technology Conference, Hangzhou, China, 10-12 May 2011; pp. 1-6.

58. Foudazi, A.; Donnell, K.M.; Ghasr, M.T. Application of Active Microwave Thermography to delamination detection. In Proceedings of the IEEE International Instrumentation and Measurement Technology Conference, Montevideo, Uruguay, 12-15 May 2014; pp. 1567-1571.

59. Levesque, P.; Deom, A.; Balageas, D. Non destructive evaluation of absorbing materials using microwave stimulated infrared thermography. In Review of Progress in Quantitative Nondestructive Evaluation; Springer: Berlin, Germany, 1993; pp. 649-654.

60. D'Ambrosio, G.; Massa, R.; Migliore, M.D.; Cavaccini, G.; Ciliberto, A.; Sabatino, C. Microwave excitation for thermographic NDE: An experimental study and some theoretical evaluations. Mater. Eval. 1995, 53, 502-508.

61. Sakagami, T.; Kubo, S.; Komiyama, T.; Suzuki, H. Proposal for a new thermographic nondestructive testing technique using microwave heating. Proc. SPIE 1999, 3700. [CrossRef]

62. Foudazi, A.; Ghasr, M.T.; Donnell, K.M. Characterization of Corroded Reinforced Steel Bars by Active Microwave Thermography. IEEE Trans. Instrum. Meas. 2015, 64, 2583-2585. [CrossRef]

63. Pieper, D.; Donnell, K.M.; Ghasr, M.T.; Kinzel, E.C. Integration of microwave and thermographic NDT methods for corrosion detection. AIP Conf. Proc. 2014, 1581, 1560-1567.

64. Foudazi, A.; Ghasr, M.T.; Donnell, K.M. Application of active microwave thermography to inspection of carbon fiber reinforced composites. In Autotestcon; IEEE: Washington, DC, USA, 2014; pp. 318-322.

65. Keo, S.A.; Brachelet, F.; Breaban, F.; Defer, D. Steel detection in reinforced concrete wall by microwave infrared thermography. NDT E Int. 2014, 62, 172-177. [CrossRef]

66. Osiander, R.; Spicer, J.W.M.; Murphy, J.C. Thermal imaging of subsurface microwave absorbers in dielectric materials. Proc. SPIE 1994, 2245. [CrossRef]

67. Bowen, M.W.; Osiander, R.; Spicer, J.W.M.; Murphy, J.C. Thermographic Detection of Conducting Contaminants in Composite Materials Using Microwave Excitation. In Review of Progress in Quantitative Nondestructive Evaluation; Thompson, D.O., Chimenti, D.E., Eds.; Springer US: Boston, MA, 1995; Volume 14, pp. 453-460.

68. Sikora, R.; Chady, T.; Szymanik, B. Infrared thermographic testing of composite materials with adhesive joints. In Proceedings of the 18th World Conference on Nondestructive Testing, Durban, South Africa, 16-20 April 2012; pp. 1-8.

69. Lee, H.; Galstyan, O.; Babajanyan, A.; Friedman, B.; Berthiau, G.; Kim, J.; Lee, K. Characterization of anisotropic electrical conductivity of carbon fiber composite materials by a microwave probe pumping technique. J. Compos. Mater. 2015, 50. [CrossRef]

70. Foudazi, A.; Edwards, C.A.; Ghasr, M.T.; Donnell, K.M. Active Microwave Thermography for Defect Detection of CFRP-Strengthened Cement-Based Materials. IEEE Trans. Instrum. Meas. 2016, 65, 1-9. [CrossRef]

71. Osiander, R.; Spicer, J.W.M.; Murphy, J.C. Microwave-source time-resolved infrared radiometry for monitoring of curing and deposition processes. Proc. SPIE 1995, 2473. [CrossRef]

72. Swiderski, W.; Szabra, D.; Wojcik, J. Nondestructive evaluation of aircraft components by thermography using different heat sources. In Proceeding of the QIRT Conference, Dubrovnik, Croatia, 24-27 September 2002; pp. 78-84.

73. Foudazi, A.; Mehdipour, I.; Donnell, K.M.; Khayat, K.H. Evaluation of steel fiber distribution in cement-based mortars using active microwave thermography. Mater. Struct. 2016, 49, 5051-5065. [CrossRef]

74. Galietti, U.; Palumbo, D.; Calia, G.; Pellegrini, M. Non destructive evaluation of composite materials with new thermal methods. In Proceedings of the 15th European Conference on Composite Materials, Venice, Italy, 24-28 June 2012.

75. Palumbo, D.; Ancona, F.; Galietti, U. Quantitative damage evaluation of composite materials with microwave thermographic technique: Feasibility and new data analysis. Meccanica 2015, 50, 443-459. [CrossRef]

76. Usamentiaga, R.; Venegas, P.; Guerediaga, J.; Vega, L.; López, I. Feature extraction and analysis for automatic characterization of impact damage in carbon fiber composites using active thermography. NDT E Int. 2013, 54, 123-132. [CrossRef] 
77. Pickering, S.; Almond, D. Matched excitation energy comparison of the pulse and lock-in thermography NDE techniques. NDT E Int. 2008, 41, 501-509. [CrossRef]

78. Gao, B.; Woo, W.L.; Tian, G.Y. Electromagnetic Thermography Nondestructive Evaluation: Physics-based Modeling and Pattern Mining. Sci. Rep. 2016, 6, 25480. [CrossRef] [PubMed]

79. Gao, B.; He, Y.; Woo, W.L.; Tian, G.Y.; Liu, J.; Hu, Y. Multidimensional Tensor-Based Inductive Thermography With Multiple Physical Fields for Offshore Wind Turbine Gear Inspection. IEEE Trans. Ind. Electron. 2016, 63, 6305-6315. [CrossRef]

80. Shankar, V.; Mohammadian, A.H. A Time-Domain, Finite-Volume Treatment for the Maxwell Equations. J. Microw. Power Electromagn. Energy 1990, 128-145. [CrossRef]

81. Harms, P.H.; Chen, Y.; Mittra, R.; Shimony, Y. Numerical Modeling of Microwave Heating Systems. J. Microw. Power Electromagn. Energy 1996, 31, 114-121. [CrossRef]

82. Vegh, V.; Turner, I.W. A hybrid technique for computing the power distribution generated in a lossy medium during microwave heating. J. Comput. Appl. Math. 2006, 197, 122-140. [CrossRef]

83. Liu, T.; Zhang, W.; Yan, S. A novel image enhancement algorithm based on stationary wavelet transform for infrared thermography to the de-bonding defect in solid rocket motors. Mech. Syst. Signal Process. 2015, 62-63, 366-380. [CrossRef]

84. Cheng, L.; Gao, B.; Tian, G.Y.; Woo, W.; Berthiau, G. Impact Damage Detection and Identification using Eddy Current Pulsed Thermography through Integration of PCA and ICA. IEEE Sens. J. 2014, 14, 1655-1663. [CrossRef]

85. Liang, T.; Ren, W.; Tian, G.Y.; Elradi, M.; Gao, Y. Low energy impact damage detection in CFRP using eddy current pulsed thermography. Compos. Struct. 2016, 143, 352-361. [CrossRef]

86. Edis, E.; Flores-Colen, I.; de Brito, J. Quasi-quantitative infrared thermographic detection of moisture variation in facades with adhered ceramic cladding using principal component analysis. Build. Environ. 2015, 94, 97-108. [CrossRef]

87. Gao, B.; Woo, W.L.; He, Y.; Tian, G.Y. Unsupervised sparse pattern diagnostic of defects with inductive thermography imaging system. IEEE Trans. Ind. Inform. 2016, 12, 371-383. [CrossRef]

88. Wang, H.; Hsieh, S.J.; Peng, B.; Zhou, X. Non-metallic coating thickness prediction using artificial neural network and support vector machine with time resolved thermography. Infrared Phys. Technol. 2016, 77, 316-324. [CrossRef]

89. Zou, H.; Huang, F. A novel intelligent fault diagnosis method for electrical equipment using infrared thermography. Infrared Phys. Technol. 2015, 73, 29-35. [CrossRef]

90. Gao, B.; Yin, A.; Tian, G.; Woo, W.L. Thermography spatial-transient-stage mathematical tensor construction and material property variation track. Int. J. Therm. Sci. 2014, 85, 112-122. [CrossRef]

91. Abdelniser, M.; Abdulbaset, A.; Ramahi, O.M. Reducing Sweeping Frequencies in Microwave NDT Employing Machine Learning Feature Selection. Sensors 2016, 16, 559. 